\title{
əThe Interdecadal Change of Summer Water Vapor over the Tibetan Plateau and Associated Mechanisms
}

\author{
CHANGYAN ZHOU \\ Institute of Plateau Meteorology, China Meteorological Administration, and Heavy Rain and Drought-Flood Disasters in \\ Plateau and Basin Key Laboratory of Sichuan Province, Chengdu, China \\ PING ZHAO \\ State Key Laboratory of Severe Weather, Chinese Academy of Meteorological Sciences, Beijing, and Collaborative \\ Innovation Center on Forecast and Evaluation of Meteorological Disasters, Nanjing University of Information Science \\ and Technology, Nanjing, China \\ JUNMING CHEN \\ State Key Laboratory of Severe Weather, Chinese Academy of Meteorological Sciences, Beijing, China
}

(Manuscript received 4 June 2018, in final form 13 February 2019)

\begin{abstract}
In recent decades, long-term changes of the Tibetan Plateau (TP) water vapor and the associated mechanisms have not been investigated fully. This study aims to examine the interdecadal change of summer TP water vapor using the monthly mean European Centre for Medium-Range Weather Forecasts interim reanalysis during 1979-2014. The results show a drier phase in the TP during 1979-94, with a subsequent wetter phase, which suggests an interdecadal variation of summer TP water vapor around the middle of the 1990s. This interdecadal variation is mainly due to a significant change of the water vapor export on the eastern boundary of the TP, which is closely associated with a summer atmospheric circulation anomaly near Lake Baikal. When a cyclonic (an anticyclonic) anomaly occurs near Lake Baikal, there is less (more) water vapor over the TP. On the interdecadal scale, the atmospheric circulation anomaly near Lake Baikal is related to an extratropical large-scale anomalous wave train over the northwestern Atlantic-East Asian region, with an eastward propagation of the anomalous wave energy from the Atlantic to East Asia. Climate model simulations further demonstrate an impact of sea surface temperature (SST) anomalies in the northwestern Atlantic on the anomalous wave train. Both the extratropical tropospheric anomalous wave train and the anomalous atmospheric circulation near Lake Baikal are successfully simulated by changing the summer northwestern Atlantic SST. Therefore the warming northwestern Atlantic is an important factor contributing to the wetting TP in recent decades.
\end{abstract}

\section{Introduction}

The Tibetan Plateau (TP), known as "the third pole," is the head source of several major rivers in Asia (e.g., the Yangtze, Yellow, Mekong, and Indus) that are feeding about $40 \%$ of the world population. The TP landatmosphere interactions affect regional and hemispheric weather, climate, and water cycle and play important roles in modifying Asian water resources (including

Denotes content that is immediately available upon publication as open access.

Corresponding author: Ping Zhao, zhaop@cma.gov.cn atmospheric water, surface water, and underground water) (Tao and Yi 1999; Zhao and Chen 2001a,b; Xu et al. 2002, 2008; Shi et al. 2009; Zhao et al. 2018). Under the influence of a strong atmospheric heat source over the TP, water vapor from the tropical Indian Ocean flows toward the TP, which maintains the convergence of water vapor and the "atmospheric water tower" over the TP (Xu et al. 2014). Meanwhile, the tropospheric water vapor over the TP can be transported vertically into the lower stratosphere (Gettelman et al. 2004; Fu et al. 2006) and horizontally into the surrounding areas, and modifies the Asian hydroclimate (Ye and Wu 1998; Ding and $\mathrm{Hu}$ 2003; Shi et al. 2009; Xu 2009; Zhou et al. 2015 ). About $75 \%$ of the total summer water vapor 
transport into the global tropical stratosphere may occur over South Asia and the TP (Gettelman et al. 2004; Fu et al. 2006). Especially under the recent global warming, the TP is experiencing a rapid warming trend (Liu and Chen 2000; Wu et al. 2007; Kang et al. 2010; Moore 2012; Chen et al. 2015), which affects regional water cycles (Held and Soden 2006; Lorenz and DeWeaver 2007; Seager et al. 2010; Sohn and Park 2010; Immerzeel et al. 2010). Water vapor over the TP also significantly correlates with summer precipitation in eastern China (Shi and Shi 2008). Therefore, it is urgent to study the TP water vapor budgets in recent decades.

Many studies have investigated water vapor budgets over the TP (e.g., Luo and Yanai 1984; Simmonds et al. 1999; Xu et al. 2002; Ueda et al. 2003; Liang et al. 2006; Sugimoto et al. 2008; Zhou et al. 2012; Feng and Zhou 2012; Chen et al. 2012; Zhuo et al. 2012; Zhang et al. 2013; Sun and Wang 2014; Curio et al. 2015; Wang et al. 2017; Zhou et al. 2017). In the southeastern TP, the water vapor imports from the western boundary of the southeastern TP exert a great effect on the interannual variability of precipitation during summer (Feng and Zhou 2012; Wang et al. 2017). Meanwhile, long-term changes of water vapor budget over the TP have also been discussed (Zhou et al. 2009, 2012; Xie et al. 2014). For example, using the 40-yr European Centre for Medium-Range Weather Forecasts Re-Analysis (ERA40), Zhou et al. (2009) examined the summer water vapor budget in the eastern TP and its surrounding areas $\left(27.5^{\circ}-35^{\circ} \mathrm{N}, 97.5^{\circ}-110^{\circ} \mathrm{E}\right)$ and revealed an evident decreasing trend of the local net water vapor income during 1958-2001. Based on the National Centers for Environmental Prediction (NCEP)-National Center for Atmospheric Research (NCAR) reanalysis data from 1979 to 2010, Xie et al. (2014) studied the variation of summer atmospheric water resources in five subareas of the TP but did not focus on the whole TP. Moreover, some studies have shown a potential flaw of the NCEP reanalysis in East Asia after 1992 on interdecadal scales (Liu et al. 2012; Zhou et al. 2017), which can affect the long-term variation of atmospheric circulation in East Asia.

The mechanisms responsible for the TP water vapor variations were also investigated. The Asian summer monsoons and the midlatitude westerlies are often thought to be two important factors affecting regional water vapor budget in the TP (e.g., Webster et al. 1998; Sugimoto et al. 2008; Schiemann et al. 2009; Li et al. 2009; Zhou et al. 2009; Feng and Zhou 2012; Xie et al. 2014; Gao et al. 2014; Wang et al. 2017). On the climatological mean map, summer water vapor in the southeastern TP mainly comes from the Arabian Sea, the Bay of Bengal, and the South China Sea (Shi and Shi 2008;
Bothe et al. 2010, 2011; Feng and Zhou 2012; Wang et al. 2017). On the interannual scale, sea surface temperature (SST) anomalies in the Pacific, the Indian Ocean, and the North Atlantic as well as the North Atlantic Oscillation (NAO) exert strong effects on water vapor budget over the TP (Liu and Yin 2001; Bothe et al. 2010, 2011; Li et al. 2014; Ren et al. 2017; Wang et al. 2017). For example, Bothe et al. (2010) suggested that the monthly wet and dry events of the TP were related to SST anomalies in the global tropics. Wang et al. (2017) documented that summer NAO could modulate the water vapor transport on the western boundary of the southern TP through influencing the meridional position of the Asian jet stream. Zhang et al. (2017) examined variations of annual precipitation in the central TP between dry and wet years and associated atmospheric moisture transports. They revealed an increase of annual precipitation in the central TP due to both an increase of the water vapor transport from the Indian Ocean and an intensification of the local hydrological recycle.

Although the previous studies have made significant progress in understanding the water vapor budget over the TP and associated mechanisms, they mainly pay attention to water vapor budgets in some subregions of the TP and their interannual variations. Some questions are not well answered. For example, in recent decades, how does the entire TP water vapor generally vary on the interdecadal time scale? What factors are responsible for such interdecadal variations? Answers to these questions could increase the understanding of interdecadal variability of the TP water vapor budget in recent decades and the intrinsic mechanisms. Therefore, this study examines the interdecadal change of water vapor over the entire TP in recent decades and gives related dynamical explanation.

The main features of the datasets, methods, and model are introduced in section 2 . In section 3 , we examine an interdecadal change of the summer TP water vapor budget and its relationships to regional precipitation and runoff. In section 4 , we explore a possible mechanism for this interdecadal change in the TP water vapor. Finally, a summary and discussion are given in section 5 .

\section{Data and methodology}

We use the monthly mean European Centre for Medium-Range Weather Forecasts interim reanalysis (ERA-Interim; Dee et al. 2011) with a horizontal resolution of $1.5^{\circ}$ in both longitude and latitude during 1979 2014. This reanalysis has been applied in the studies of water vapor budget over the TP (e.g., Gao et al. 2014; Curio et al. 2015; Zhou et al. 2017; Zhang et al. 2017). 


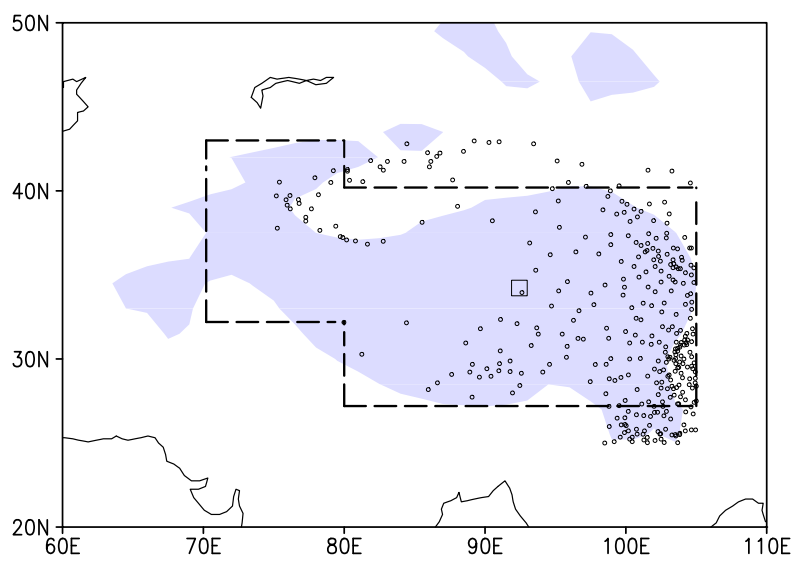

FIG. 1. Distribution of Chinese rain gauge stations (circles) in the TP and adjacent areas. Shaded areas are for the topography above $2000 \mathrm{~m}$, dashed lines enclose the region of the TP in this study (including the regions $32.2^{\circ}-43^{\circ} \mathrm{N}, 70.2^{\circ}-80^{\circ} \mathrm{E}$ and $27.2^{\circ}-40.2^{\circ} \mathrm{N}$, $80^{\circ}-105^{\circ} \mathrm{E}$ ), and the small box indicates the position of the Tuotuo River hydrometric station $\left(34.22^{\circ} \mathrm{N}, 92.44^{\circ} \mathrm{E}\right)$.

Bao and Zhang (2013) evaluated the NCEP, NCEP Climate Forecast System Reanalysis (CFSR), ERA-40, and ERA-Interim reanalysis products with sounding observations in 1998. Their results showed that the horizontal wind, temperature, and relative humidity of ERA-Interim are highly correlated to the sounding observations at different vertical levels. The 19792014 monthly accumulated rainfall data (after the quality control) at 355 gauge stations near the TP come from the National Meteorological Information Center of the China Meteorological Administration (Fig. 1). The simultaneous monthly mean precipitation rate data of the Climate Prediction Center Merged Analysis of Precipitation (CMAP) with a horizontal resolution of $2.5^{\circ}$ (Xie and Arkin 1997) are also used. The general consistency between the CMAP and gauge precipitation in the TP has been demonstrated (e.g., You et al. 2015). The 1979-2012 monthly observation data of surface runoff at the Tuotuo River station (Fig. 1) from the Hydrology and Water Resources Survey Bureau of Qinghai Province are utilized to examine a variation of runoff in the central TP. Moreover, we also use the monthly mean SST of the Hadley Centre Sea Ice and Sea Surface Temperature dataset (HadISST) with a horizontal resolution of $1^{\circ}$ (Rayner et al. 2003).

The vertically integrated water vapor flux $(Q)$, the atmospheric precipitable water vapor (PW), and the water vapor budget $(B)$ are utilized to analyze variations of water vapor over the TP:

$$
Q=-\frac{1}{g} \int_{p_{s}}^{p} q \mathbf{V} d p
$$

$$
\begin{aligned}
\mathrm{PW} & =-\frac{1}{g} \int_{600}^{p} q d p, \text { and } \\
B & =\oint Q d l .
\end{aligned}
$$

In most of the TP, the climatological mean surface pressure is around $600 \mathrm{hPa}$. Following Wang et al. (2009), PW is the vertically integrated water vapor from $600 \mathrm{hPa}$ to $p$ (from $p_{s}$ when $p_{s}<600 \mathrm{hPa}$ ); $p_{s}$ is the surface pressure; $p$ is set to be $300 \mathrm{hPa}$; $g$ is the gravity acceleration; $q$ is the specific humidity; $\mathbf{V}$ is the horizontal wind vector; and $l$ is the boundary curve of the TP (shown in Fig. 1). The water vapor budget over the TP enclosed by the curve $l$ is defined as $B_{T}$, including the water vapor budgets on the southern $\left(B_{S}\right)$, northern $\left(B_{N}\right)$, eastern $\left(B_{E}\right)$, and western $\left(B_{W}\right)$ boundaries of $l$. Here, the letters N, E, W, and S stand for the northern, eastern, western, and southern boundaries, respectively; $B_{T}$ is equal to the sum (total) of the budgets on these four boundaries. Because more observation data in the adjacent areas of the TP are assimilated into the atmospheric reanalysis fields, $B_{T}$ calculated by $B$ can more reasonably estimate the entire TP water vapor compared to the regional mean of PW. The positive (negative) value of $B_{T}$ indicates a net water vapor income (output) and therefore the whole region acts as water vapor sink (source). The positive (negative) values of $B_{N}, B_{S}, B_{E}$, and $B_{W}$ indicate water vapor imports (exports) on the boundary of the region.

The NCAR Community Atmospheric Model version 3 (CAM3) (Collins et al. 2004) is used to investigate a possible mechanism behind the interdecadal change of the TP water vapor budget. This model has been applied extensively in the research of climate, and it can reasonably capture major features of global and Asian atmospheric circulation and climate (e.g., Hack et al. 2006; Deser and Phillips 2009; Kim and Wang 2007; Zhao et al. 2011, 2012).

A 9-yr filter method is used to extract the interannual or interdecadal component of a variable. Correlation, regression, and composite analyses are utilized in detecting the relationships between pairs of variables. The Student's $t$ test or the Monte Carlo simulation is used to assess the statistical significance. All the significances are at the $90 \%$ confidence level unless otherwise stated. Averages of June-August (JJA) are used to represent summer conditions.

\section{Variations of summer water vapor over the TP}

\section{a. Climatological mean features}

Figure 2a shows the horizontal distribution of summer PW during 1979-2014. In this figure, large PW values 
(a)

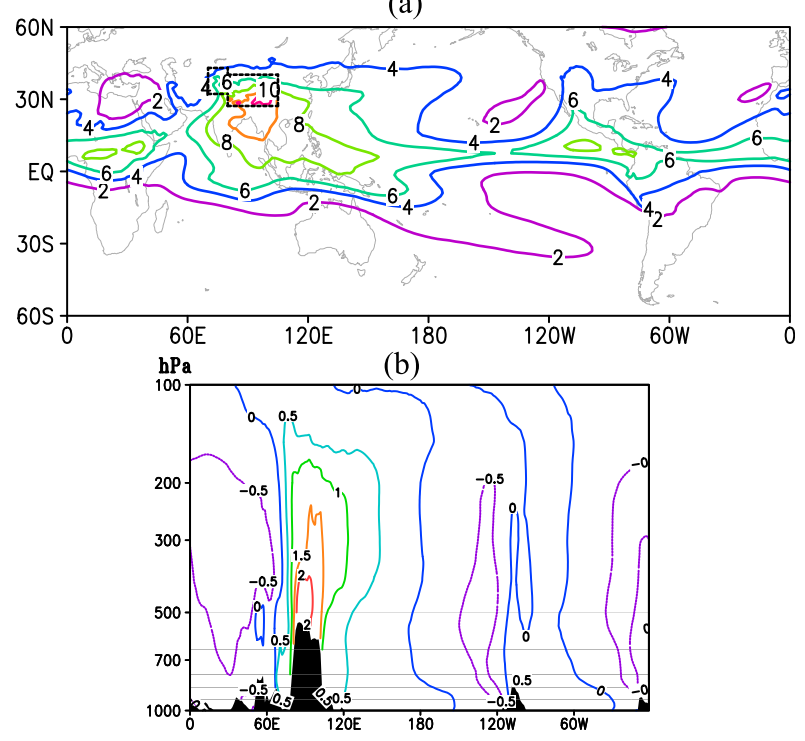

(c)

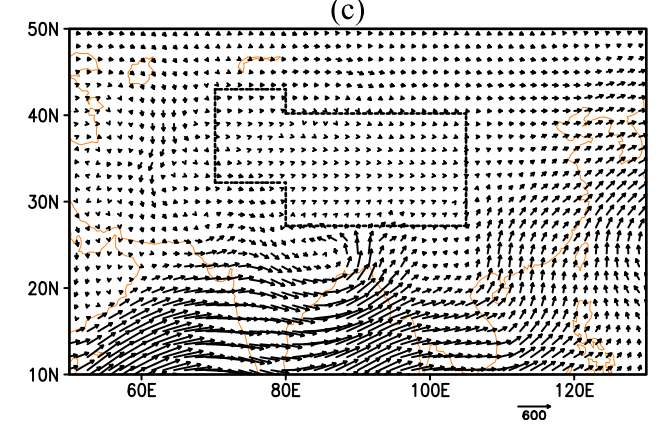

FIG. 2. (a) Distribution of the climatological (1979-2014) summer PW $\left(\mathrm{kg} \mathrm{m}^{-2}\right)$; (b) as in (a), but for the longitude-height cross section of summer $D$ along $30^{\circ} \mathrm{N}$, in which shaded areas show the topography; and (c) as in (a), but for summer $Q\left(\mathrm{~kg} \mathrm{~m}^{-1} \mathrm{~s}^{-1}\right)$.

appear in the TP and its adjacent areas, with the maximum value exceeding $12 \mathrm{~kg} \mathrm{~m}^{-2}$ in the southeastern TP. Figure $2 \mathrm{~b}$ shows the longitude-height cross section of summer $D$ along $30^{\circ} \mathrm{N}$, where $D=(q-\bar{q}) / \bar{q}$ (Zhang et al. 2013) and $\bar{q}$ is the zonal mean of $q$. Positive values of $D$ above 1 appear in the TP, with the central value of 2 between 600 and $400 \mathrm{hPa}$. This result indicates that the summer wettest center of the globe in the middle-upper troposphere occurs over the TP, which supports the TP as a "moist pool" in the middle-upper troposphere (Wang et al. 2009; Zhou et al. 2017).

Figure $2 \mathrm{c}$ shows the climatological mean of summer $Q$. In this figure, water vapor over the Indian Ocean (extratropical West Asia) is transported into the TP from the southern (western) boundary, and water vapor over the TP is also exported from the eastern boundary to the downstream areas. On the average, the southerly, westerly, and northerly wind transports water vapor of $104.1 \times 10^{6}, 53.6 \times 10^{6}$, and $17.9 \times 10^{6} \mathrm{~kg} \mathrm{~s}^{-1}$, respectively, from the respective southern, western, and northern boundaries into the TP during summer. The water vapor export from the eastern boundary of the TP is $54.2 \times 10^{6} \mathrm{~kg} \mathrm{~s}^{-1}$. The net water vapor income is $121.4 \times 10^{6} \mathrm{~kg} \mathrm{~s}^{-1}$ in the TP. On the climatology, therefore, the southerly wind is a dominant factor contributing to the TP water vapor budget.

\section{b. Variations of the TP water vapor}

The summer $B_{T}$ over the TP generally exhibits an increase during 1979-2014, with a trend of $6.4 \times$ $10^{5} \mathrm{~kg} \mathrm{~s}^{-1} \mathrm{yr}^{-1}$ (significant at the $95 \%$ confidence level), which indicates an obvious wetting trend. Figure 3 a shows the temporal curve of the standardized summer $B_{T}$. The negative phase of $B_{T}$ mainly occurs during 1979-94, with a positive phase during the subsequent period. This feature implies an interdecadal increase of the TP water vapor during 1995-2014 relative to 1979-94. Meanwhile, summer $B_{T}$ also exhibits obvious interannual variations, with drier years in 1982, 1983, and 1986 and wetter years in 1995, 1998, and 2003. These drier and wetter years are remarkably distinct from those in Zhang et al. (2017). This difference is likely due to the different study regions and seasons. Moreover, they also showed an obvious interdecadal variation of precipitation in the west-central TP around the middle 1990s.

A correlation analysis indicates that during summer, $B_{T}$ has a correlation of $0.34,0.54$, and -0.39 (significant above the $95 \%$ confidence level) with the simultaneous $B_{W}, B_{S}$, and $B_{N}$, respectively, during 1979-2014 and has a weak correlation with $B_{E}(0.25$; not significant at the $90 \%$ confidence level). This result suggests close links between $B_{T}$ and each of $B_{W}, B_{S}$, and $B_{N}$. Figure $3 \mathrm{~b}$ shows the temporal curves of $B$ on the boundaries of the TP during summer. Generally speaking, $B_{S}, B_{W}$, and $B_{N}$ are positive, which indicates the imports of water vapor into the TP from the southern, western, and northern boundaries. Both $B_{S}$ and $B_{W}$ show increasing trends, with their linear trends of $3.2 \times$ $10^{5} \mathrm{~kg} \mathrm{~s}^{-1} \mathrm{yr}^{-1}$ and $0.9 \times 10^{5} \mathrm{~kg} \mathrm{~s}^{-1} \mathrm{yr}^{-1}$. However, $B_{N}$ shows a significant reducing trend $\left(-6.3 \times 10^{5} \mathrm{~kg} \mathrm{~s}^{-1} \mathrm{yr}^{-1}\right)$. Meanwhile, $B_{E}$ is negative and has an increasing trend of $8.6 \times 10^{5} \mathrm{~kg} \mathrm{~s}^{-1} \mathrm{yr}^{-1}$ during 1979-2014, which indicates the weakening of the water vapor export on the eastern boundary of the TP, and also contributes to an increase of the TP water vapor in recent decades.

Referring to the interdecadal varying feature of summer $B_{T}$ (shown in Fig. 3a), we use 1979-94 and 1995-2014 to represent dry and wet phases of the TP, respectively. Figure $3 \mathrm{c}$ further shows the summer PW difference between the dry and wet phases (1979-94 minus 1995-2014, similarly hereinafter). It is shown that there are generally significant negative differences in the TP and its south, with central values below -0.9 in the 
(a)

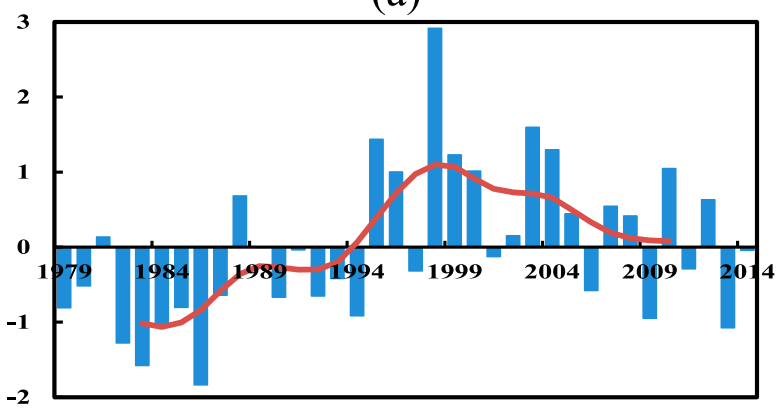

(b)

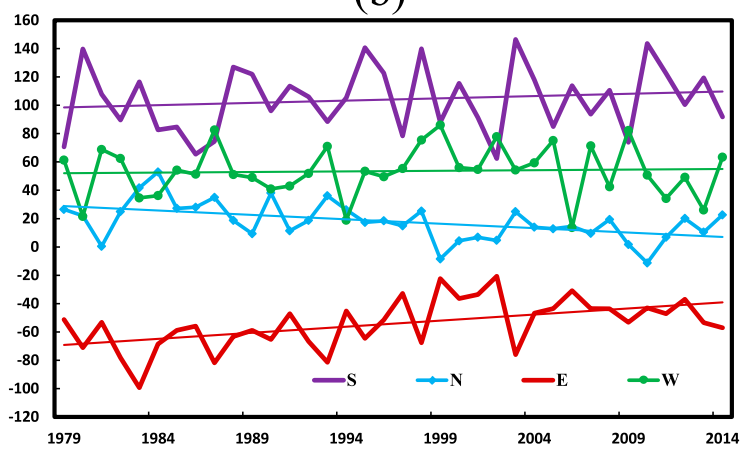

(c)

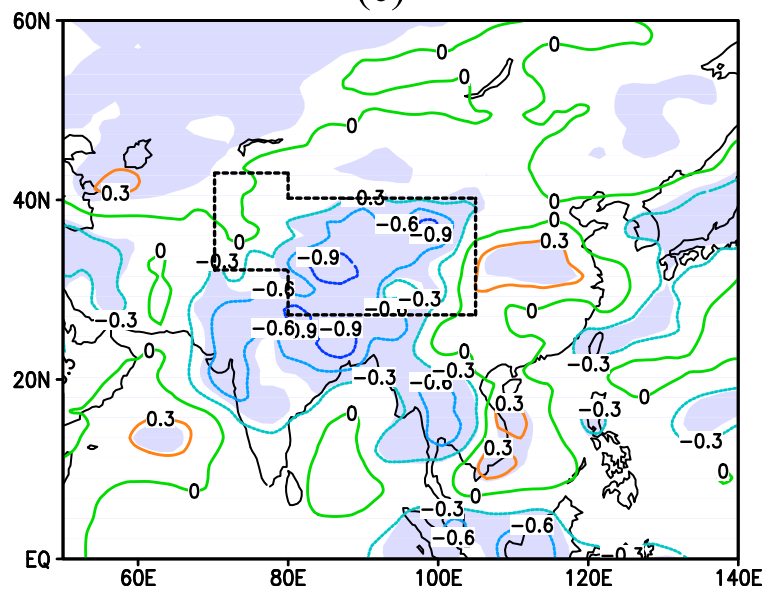

FIG. 3. (a) The standard time series of summer $B_{T}$ (blue column) during 1979-2014 and its interdecadal component (red line); (b) the time series of $B_{N}$ (blue), $B_{W}$ (green), $B_{S}$ (purple), and $B_{E}$ (red) $\left(10^{6} \mathrm{~kg} \mathrm{~s}^{-1}\right)$ during $1979-2014$; and (c) the composite difference of summer PW ( $\mathrm{kg} \mathrm{m}^{-2}$; 1979-94 minus 1995-2014), in which the shaded regions are significant at the $90 \%$ confidence level. The thin lines in (b) indicate linear trends of $B_{N}, B_{W}, B_{S}$, and $B_{E}$.

central and northeastern parts of the TP. This feature further supports the increase of the TP water vapor in 1995-2014 relative to 1979-94 (shown in Fig. 3a). Table 1 shows summer $B$ between the dry and wet phases. On an average over the entire TP, $B_{T}$ is $110.0 \times$ $10^{6} \mathrm{~kg} \mathrm{~s}^{-1}$ during $1979-94$ and $130.6 \times 10^{6} \mathrm{~kg} \mathrm{~s}^{-1}$ during 1995-2014, with a difference of $-20.6 \times 10^{6} \mathrm{~kg} \mathrm{~s}^{-1}$
TABLE 1. The summer water vapor budgets $\left(10^{6} \mathrm{~kg} \mathrm{~s}^{-1}\right)$ in the TP during 1979-94 and 1995-2014 and their differences (1979-94 minus 1995-2014), in which the differences indicated by an asterisk $(*)$ are significant at the $95 \%$ confidence level.

\begin{tabular}{lrcccc}
\hline \hline & \multicolumn{1}{c}{$B_{S}$} & $B_{N}$ & $B_{E}$ & $B_{W}$ & $B_{T}$ \\
\hline 1979-94 & 99.4 & 26.1 & -65.4 & 49.9 & 110.0 \\
1995-2014 & 107.9 & 11.4 & -45.2 & 56.5 & 130.6 \\
Difference & -8.5 & $14.7^{*}$ & $-20.2^{*}$ & -6.6 & $-20.6^{*}$ \\
\hline
\end{tabular}

between the two phases, which indicates a wetter climate in recent decades. This wetting mainly results from a decrease of the water vapor export on the eastern boundary, with a significant difference of $-20.2 \times 10^{6}$. $\mathrm{kg} \mathrm{s}^{-1}$ between 1979-94 and 1995-2014. On the interdecadal scale, therefore, the change of the water vapor budget on the eastern boundary plays a dominant role in modulating the summer TP water vapor. Meanwhile, the water vapor imports from the southern and western boundaries also contribute to the increases of the TP water vapor during 1995-2014, with their values of $8.5 \times$ $10^{6} \mathrm{~kg} \mathrm{~s}^{-1}$ and $6.6 \times 10^{6} \mathrm{~kg} \mathrm{~s}^{-1}$, respectively. The water vapor import from the northern boundary decreases during 1995-2014, with a difference of $14.7 \times 10^{6} \mathrm{~kg} \mathrm{~s}^{-1}$.

Corresponding to the increase of the TP water vapor in recent decades, the time series of summer PW exhibits an increasing trend of $0.019 \mathrm{~kg} \mathrm{~m}^{-2} \mathrm{yr}^{-1}$ (significant at the 99\% confidence level) during 1979-2014 (Fig. 4a) and has a significant correlation of 0.67 with $B_{T}$ during 1979-2014. The interdecadal change of water vapor influences the local precipitation. Figure $4 \mathrm{~b}$ shows the composite difference of summer gauge rainfall between 1979-94 and 1995-2014. In this figure, negative anomalies of rainfall almost cover the whole TP (except for the eastern and northeastern parts), which indicates an increase of summer rainfall in 1995-2014 relative to 197994. For example, the summer rainfall increases by 12.2 , 24.2, 17.7, 26.1, and $25.3 \mathrm{~mm}$ at Gaize, Lhasa, Shenzha, Nanmulin, and Mangkang, respectively. The composite difference of the CMAP rainfall between 1979-94 and 1995-2014 shows the similar negative values in the TP (Fig. 4c). Figure 4a also shows the temporal curve of the TP summer mean CMAP precipitation. The CMAP precipitation displays an increasing trend of $0.01 \mathrm{~mm} \mathrm{day}^{-1} \mathrm{yr}^{-1}$ (significant at the $95 \%$ confidence level) during 1979-2014 and has a correlation of 0.56 with $B_{T}$ during 1979-2014. This increase in rainfall has been noted by Zhang et al. (2017). The wetting TP also causes a synchronous increase in the local runoff. Some studies revealed an increase in lake areas and water level in most parts of the TP since the 1990s (Yao et al. 2012; Wan et al. 2014; Yang et al. 2014; Chen et al. 2015). At the Tuotuo River hydrological station $\left(34.22^{\circ} \mathrm{N}\right.$, 
(a)

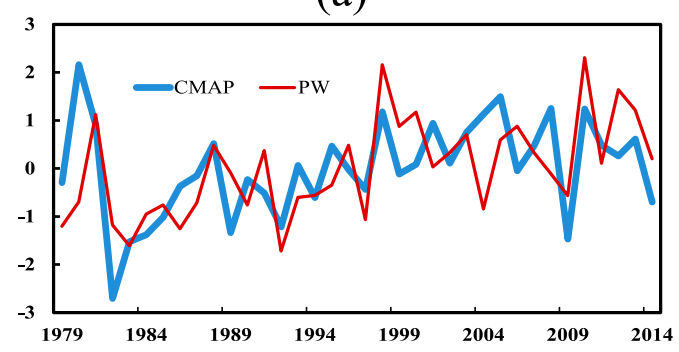

(b)

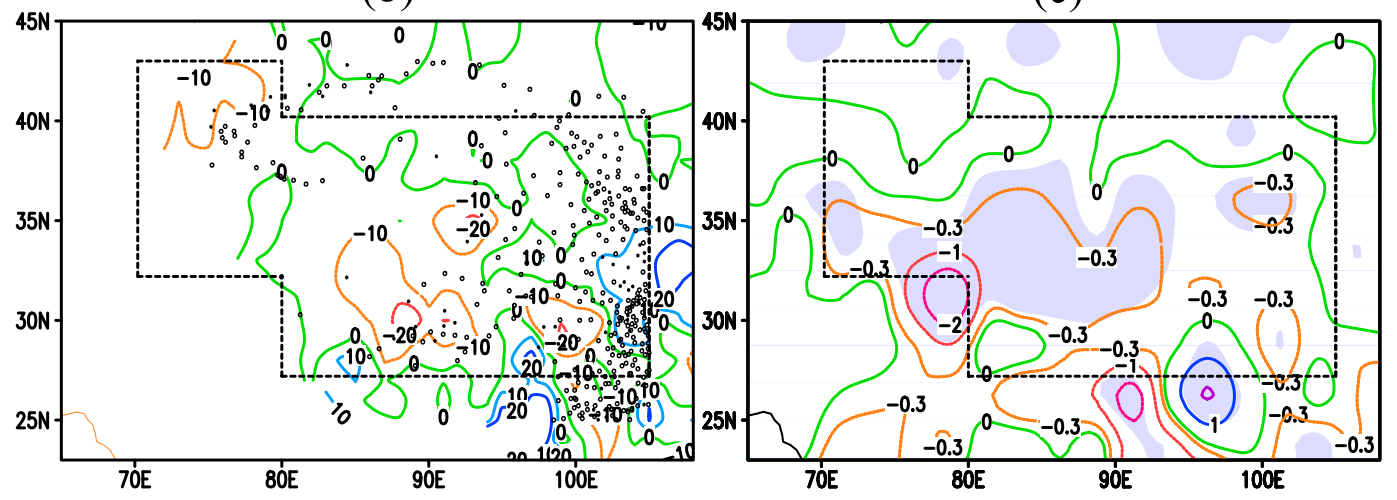

(d)

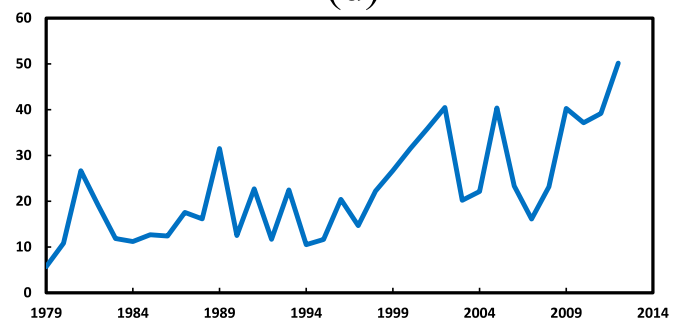

(e)

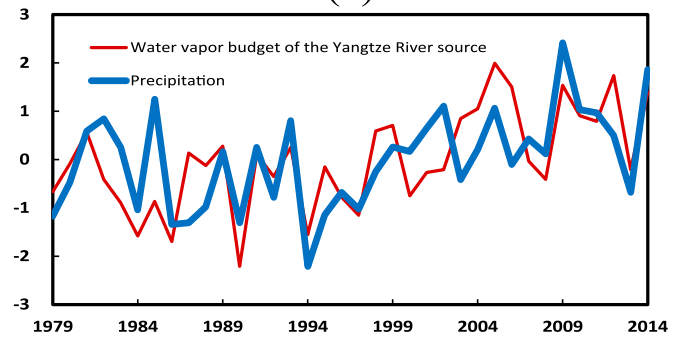

FIG. 4. (a) The standard time series of summer PW and CMAP precipitation over the TP during 1979-2014. (b) Composite difference of summer gauge rainfall (mm; 1979-94 minus 1995-2014), in which the black solid circles are significant at the $90 \%$ confidence level. (c) As in (b), but for CMAP rainfall, in which shaded areas are significant at the $90 \%$ confidence level. (d) Time series of summer surface runoff $\left(10^{7} \mathrm{~m}^{3} \mathrm{~s}^{-1}\right)$ at the Tuotuo River station during 1979-2012. (e) The standardized series of summer water vapor budget in the Yangtze River source $\left(32^{\circ}-36^{\circ} \mathrm{N}, 90^{\circ}-99^{\circ} \mathrm{E}\right)$ and summer rainfall at the Tuotuo River station during 1979-2014.

$92.44^{\circ} \mathrm{E}$ ) of the central TP (Fig. 4d), summer surface runoff shows a remarkable increase, with a mean value of $16.0 \times 10^{7}$ and $28.6 \times 10^{7} \mathrm{~m}^{3} \mathrm{~s}^{-1}$ during 1979-94 and 1995-2012, respectively, and a difference of $-12.6 \times$ $10^{7} \mathrm{~m}^{3} \mathrm{~s}^{-1}$ (significant at the $99.9 \%$ confidence level) between these two periods. The variation of surface runoff may be associated with that of the local water vapor. For example, at the Tuotuo River station of the source of the Yangtze River (in the central part of the TP), the linear trend of summer surface runoff at the 
Tuotuo River station is $7.8 \times 10^{6} \mathrm{~m}^{3} \mathrm{~s}^{-1} \mathrm{yr}^{-1}$ during 1979-2012, significant at the $99.9 \%$ confidence level. The variations of the water vapor budget in the Yangtze River source and precipitation at the Tuotuo River station are highly consistent with that of the local surface runoff (Fig. 4e). During 1979-2012, the correlation coefficient is 0.71 between the runoff and precipitation at Tuotuo River station. Furthermore, the correlation coefficient between the Tuotuo River runoff and the water vapor budget of the Yangtze River source is 0.68 during 1979-2012, significant at the 99\% confidence level. These results suggest the effects of both water vapor budget and precipitation in the Yangtze River source on the local runoff. Although the melting of glacier also affects the surface runoff in the Tuotuo River (e.g., Yang et al. 2003; Wang et al. 2013; Jin et al. 2013; Zhang et al. 2014; Qian et al. 2014; Tang et al. 2018, etc.), this effect is likely less than precipitation (e.g., Qian et al. 2014; Tang et al. 2018). Evaporation is another important factor to the hydrological cycle. Some studies showed that the pan evaporation had a decreasing trend on the TP over the past decades (Zhang et al. 2007, 2009; Liu et al. 2011; Yang et al. 2011, 2014), which might also contribute to the increase of local surface runoff.

Based on the foregoing analyses, the TP has been getting wetter since the 1980s during summer, with a drier climate before 1995 and a wetter climate in the subsequent decades. This wetting accompanies the increases of the local rainfall and surface runoff, implying more abundant water resource in the TP. The increased summer water vapor is mainly owing to a decrease of the water vapor export on the eastern boundary of the TP. Then, what factors are responsible for the interdecadal change of the TP water vapor in recent decades? In the following section, we give a dynamical explanation.

\section{Factors affecting the $T P$ interdecadal wetting}

\section{a. Atmospheric circulation}

The anomalies of 500-hPa geopotential height associated with the interdecadal variation of the TP water vapor are examined. Figure 5a shows the composite difference of summer 500-hPa geopotential height between 1979-94 and 1995-2014. In the figure, significant negative anomalies appear near Lake Baikal, with the central value of $-20 \mathrm{gpm}$, indicating a low pressure anomaly near Lake Baikal. On the height-latitude cross section map along the anomalous center near Lake Baikal (Fig. 5b), negative anomalies are deep in the troposphere, stretching from surface to $50 \mathrm{hPa}$, with the anomalous center of $-45 \mathrm{gpm}$ near $200 \mathrm{hPa}$. Figure $5 \mathrm{c}$ further shows the correlation pattern between the interdecadal components of summer $B_{T}$ (shown in Fig. 3a) and the simultaneous 500-hPa geopotential height during 1983-2010. It is seen that significant positive correlations appear near Lake Baikal, with the maximum value of 0.7 (significant at the $95 \%$ confidence level). This feature is consistent with that in Fig. 5a, supporting the relationship that the low pressure (high pressure) anomaly near Lake Baikal accompanies the interdecadal decrease (increase) of the TP water vapor. Moreover, we also examine the interannual relationship between summer $B_{T}$ and simultaneous $500-\mathrm{hPa}$ geopotential height during 1983-2010. On this time scale, significant positive correlations appear to the northwest of the TP, with a central value above 0.6 (Fig. 5d). Positive correlations also appear in northeast Asia and the subtropics of Asia and the western Pacific. Weak correlations appear near Lake Baikal. It is evident that this correlation pattern is distinct from that on the interdecadal scale (Fig. $5 \mathrm{c}$ ). The correlations between the interdecadal or interannual component of summer $B_{T}$ and the simultaneous $200-\mathrm{hPa}$ geopotential height during 1983-2010 are also calculated. The correlation patterns are consistent with those at $500 \mathrm{hPa}$.

Associated with the anomalous low pressure near Lake Baikal is an anomalous cyclonic circulation at $500 \mathrm{hPa}$, with the circulation center near $47.5^{\circ} \mathrm{N}, 103^{\circ} \mathrm{E}$ (Fig. 6a). The westerly wind anomaly to the south of the anomalous cyclonic center flows out of the TP from the eastern boundary, and the northwesterly wind anomaly to the west of the anomalous cyclonic center flows into the TP from the northern boundary. The wind anomalies are weak on the western and southern boundaries. Figure $6 \mathrm{~b}$ shows the composite difference of summer $Q$. Corresponding to the $500-\mathrm{hPa}$ anomalous cyclone (shown in Fig. 6a), a significant anticlockwise transport anomaly of $Q$ appears to the north of the TP (Fig. 6b). The southeastward and eastward water vapor flux anomalies greatly affect the TP water vapor budget through the northern and eastern boundaries of the TP, respectively. Compared to the climate mean state (shown in Fig. 2c), the eastward water vapor transport anomaly on the eastern boundary significantly increases the water vapor export, acting as a major contributor to the drier climate of the TP in 1979-94 relative to 1995-2014 (Table 1). Because an extreme value of $B_{T}$ over the TP occurs in 1998 (Fig. 3a), we repeat the similar composite analysis after removing 1998 and obtain the consistent results with those of Figs. 3c, 4b, 4c, and 5. This result shows that when not including the 1998 data, there are no substantial changes of the results. Thus the composites with the full data can reflect general features of the periods.

Referring to the correlation pattern between the interdecadal components of summer $B_{T}$ and the simultaneous geopotential height and the anomalous center 
(a)

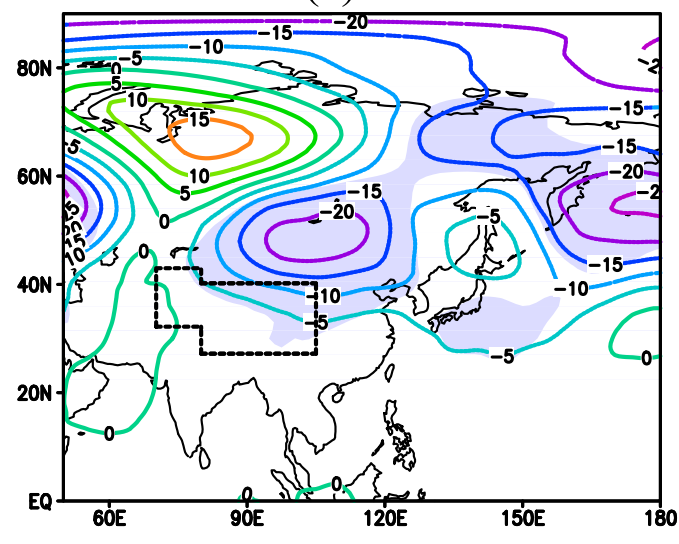

(c)

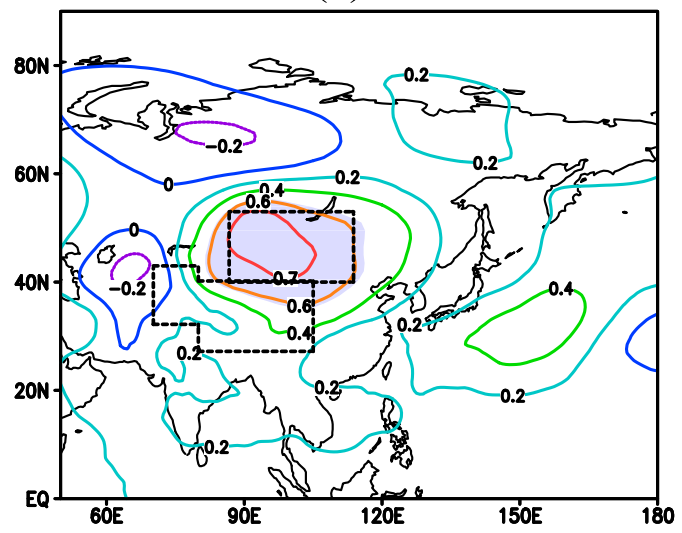

(b)

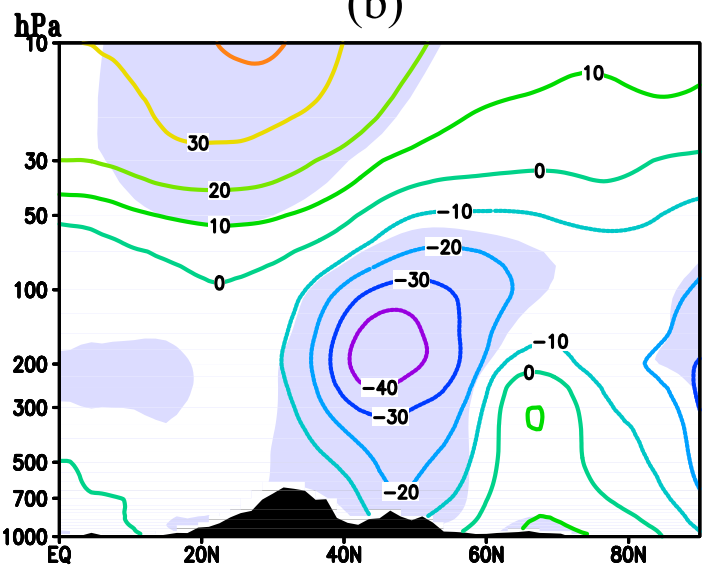

(d)

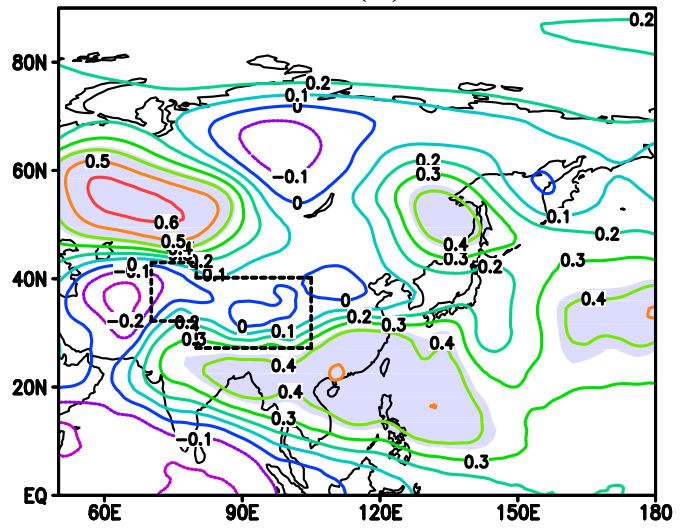

FIG. 5. (a) The composite difference of summer 500-hPa geopotential height (gpm) (1979-94 minus 1995-2014). (b) As in (a), but for the height-latitude cross section along $102^{\circ} \mathrm{E}$; (c) correlation between summer $B_{T}$ and the simultaneous $500-\mathrm{hPa}$ geopotential height on the interdecadal scale, in which the box $\left(40^{\circ}-53^{\circ} \mathrm{N}, 86.7^{\circ}-113.8^{\circ} \mathrm{E}\right)$ indicates the key region near Lake Baikal; and (d) as in (c), but for the interannual scale. Shaded regions are significant at the $90 \%$ confidence level.

position in Fig. 5b (with the strongest negative anomalies of geopotential height near $200 \mathrm{hPa}$ ), a circulation index near Lake Baikal (called the Lake Baikal circulation index) is defined as the regional mean of summer 200 -hPa geopotential height over the region $40^{\circ}-53^{\circ} \mathrm{N}$, $86.7^{\circ}-113.8^{\circ} \mathrm{E}$. This index is significantly correlated to the summer $B_{E}$ (with a correlation coefficient of 0.81 during 1979-2014). In general, on the interdecadal scale, the TP water vapor is closely related to the anomalous atmospheric circulation near Lake Baikal. Then, what factors are responsible for the circulation anomaly near Lake Baikal during summer?

\section{b. A mechanism for atmospheric circulation anomaly near Lake Baikal}

Ding and Wang (2005) proposed that a summer circumglobal teleconnection (CGT) exists in the Northern Hemisphere on the interannual time scale. The Indian- east Asian summer monsoon teleconnection (Wang et al. 2001), the Silk Road pattern (Enomoto et al. 2003), and the Tokyo-Chicago express (Lau et al. 2004) were believed to be regional manifestations of this CGT pattern (Ding and Wang 2005). In this section, we also examine the atmospheric teleconnection associated with the interdecadal change of the TP water vapor. Because the strongest negative anomalies of geopotential height appear near $200 \mathrm{hPa}$ (Fig. 5b), we examine eddy geopotential height anomalies at this level. Figure 7a shows the composite difference of summer 200-hPa eddy geopotential height between 1979-94 and 19952014, where the eddy geopotential height is defined as a difference of geopotential height from its zonal mean. In the figure, an anomalous wave train appears in the extratropics from the northwestern Atlantic to East Asia. The negative anomalies appear in Baffin Bay, central Europe, and Lake Baikal, while the positive anomalies 
(a)

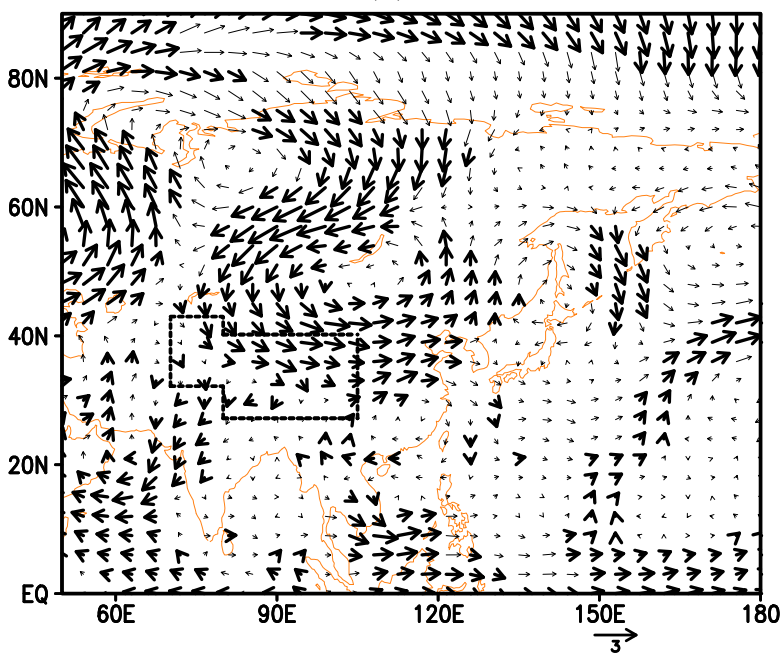

(b)

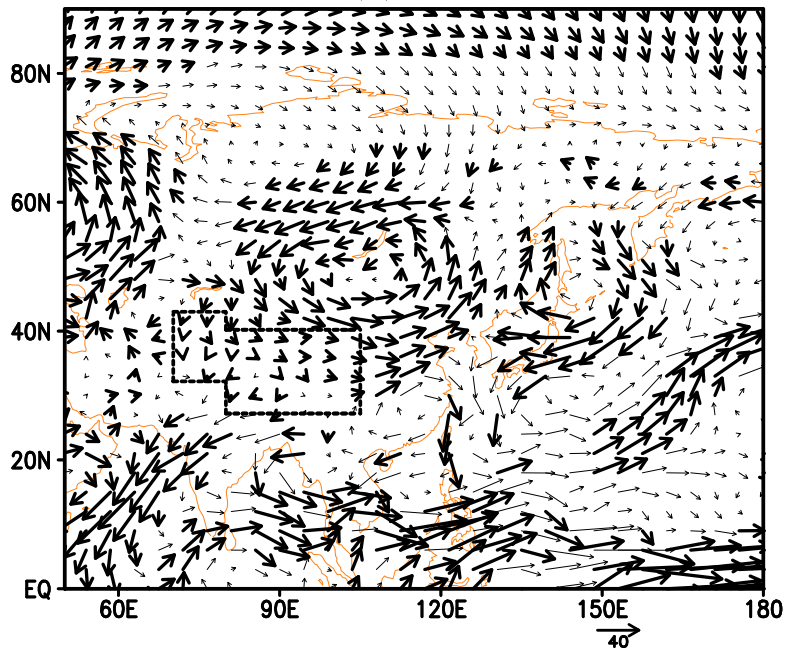

FIG. 6. (a) As in Fig. 5a, but for summer 500-hPa wind ( $\left.\mathrm{m} \mathrm{s}^{-1}\right)$, in which thick vectors are significant at the $90 \%$ confidence level. (b) As in (a), but for summer $Q\left(\mathrm{~kg} \mathrm{~m} \mathrm{~s}^{-1}\right)$.

appear in the central-eastern Atlantic and western Asia. The negative or positive anomalies are deep in the troposphere, with their centers appearing generally in the upper troposphere (between 300 and $200 \mathrm{hPa}$ ) (Fig. 7b). This result shows that the cyclonic circulation anomaly near Lake Baikal links a larger-scale anomalous wave train in middle and high latitudes from the western Atlantic to East Asia. It is noted that the anomalous wave train in middle and high latitudes (Fig. 7a) also displays a circumglobal teleconnection pattern that stretches from the northwestern Atlantic to North America, and its centers exhibit a barotropic structure (Fig. 7b). However, this teleconnection is distinct from the CGT on the interannual time scale in path and central position.
Figure 7a also shows the wave activity flux (Takaya and Nakamura 1997, 2001) that may indicate the propagation of wave energy. In this figure, the large westward wave activity flux above $1.0 \mathrm{~m}^{2} \mathrm{~s}^{-2}$ appears in the extratropical North Atlantic and then stretches to East Asia via Europe, which implies a propagation of the anomalous wave energy from the extratropical North Atlantic toward East Asia. Is the anomalous wave train triggered by an Atlantic SST change?

Figure 8a shows the composite difference of summer SST in the North Atlantic Ocean between 1979-94 and 1995-2014. In this figure, significant negative anomalies of SST appear in the extratropical northwestern Atlantic, with the central value below $-1.8^{\circ} \mathrm{C}$. Referring to the position of the negative SST anomalies, we define a northwestern Atlantic SST index as the summer regional mean value over $67^{\circ}-39^{\circ} \mathrm{W}, 40^{\circ}-55^{\circ} \mathrm{N}$ (shown in Fig. 8a). Figure $8 \mathrm{~b}$ shows the regressed $200-\mathrm{hPa}$ eddy geopotential height against the Atlantic SST index (with an opposite sign for a convenient comparison with Fig. 7a) on the interdecadal scale. It is seen from this figure that an anomalous wave train appears in the extratropical Northern Hemisphere, with the negative anomalies in Baffin Bay, central Europe, and southern Lake Baikal and the positive anomalies in the centraleastern Atlantic and western Asia. This anomalous feature is very similar to that associated with the interdecadal change of the TP water vapor (shown in Fig. 7a), which implies that a decrease (an increase) of the summer Atlantic SST corresponds to a significant cyclonic (anticyclonic) circulation anomaly near Lake Baikal. Thus, both the cyclonic or anticyclonic circulation anomaly near Lake Baikal and the extratropical anomalous wave train are related to the northwestern Atlantic. Figure $8 \mathrm{c}$ shows the temporal curves of summer $B_{E}$ of the TP, the Lake Baikal circulation index and the northwestern Atlantic SST index. They also exhibit the similar variation on the interdecadal time scale, further demonstrating a close link among these factors.

To demonstrate this impact of the northwestern Atlantic SST anomaly, we perform two sensitivity experiments by the CAM3 climate model. One is the experiment CAM3_Control, in which the monthly climatological (1981-2001) SST in the original CAM3 model is used (Collins et al. 2004). The other is consistent to the experiment CAM3_Control but the anomalous pattern of SST in the northwestern Atlantic region $\left(40^{\circ}-55^{\circ} \mathrm{N}, 67^{\circ}-39^{\circ} \mathrm{W}\right.$; shown in the box of Fig. $\left.8 \mathrm{a}\right)$ is added to the monthly climatological SST in summer, called the CAM3_N. For each experiment, the CAM3 model is integrated for 50 years and the model output in the last 30 years is analyzed. 
(a)
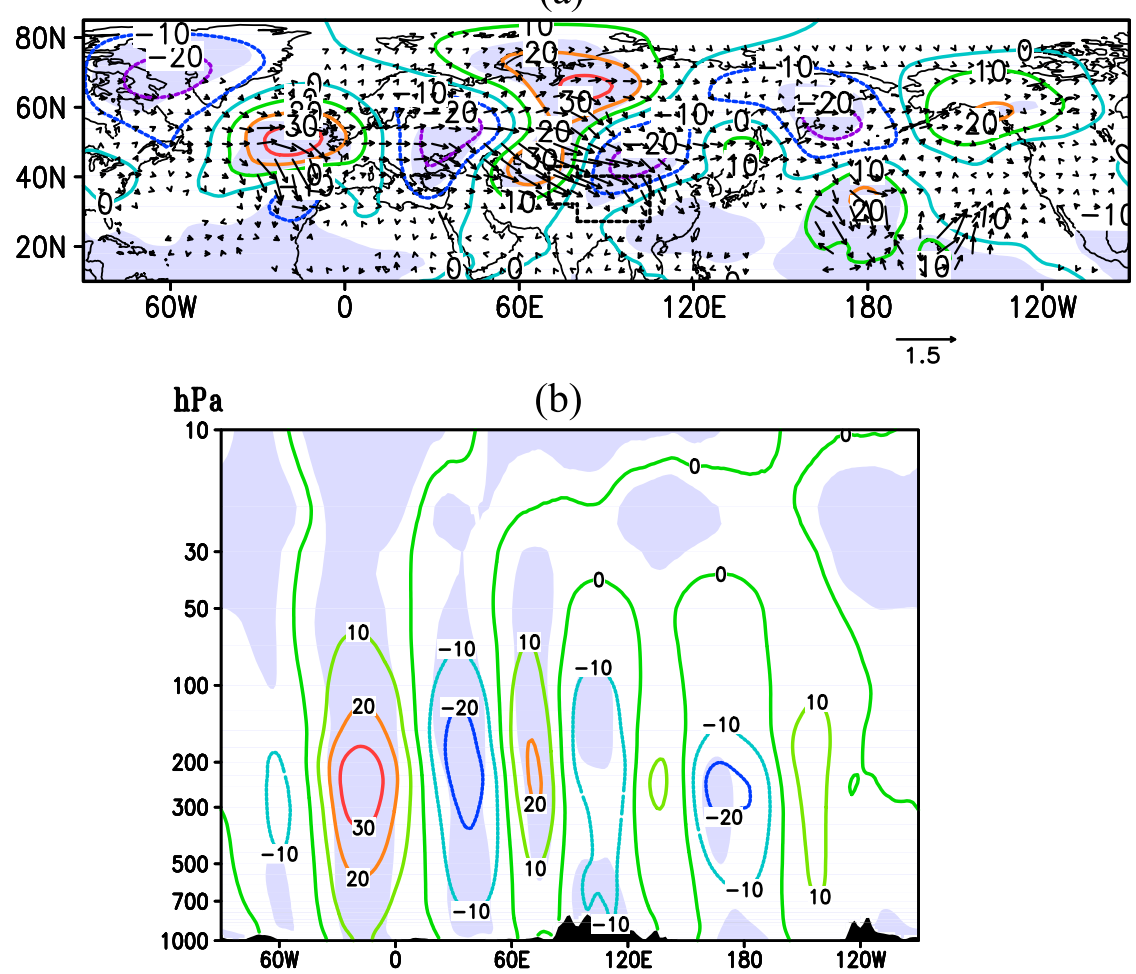

FIG. 7. (a) As in Fig. 5a, but for summer 200-hPa eddy geopotential height (contours; gpm) and the wave activity flux (vectors; $\mathrm{m}^{2} \mathrm{~s}^{-2}$ ); and (b) as in (a), but for the longitude-height cross section of summer eddy geopotential height along $50^{\circ} \mathrm{N}$.

Figure 9 shows the composite difference of summer 200hPa eddy geopotential height between the experiments CAM3_N and CAM3_Control. It appears that an anomalous wave train is induced over the extratropics from the northwestern Atlantic to East Asia. The negative anomalous centers appear in Baffin Bay, central Europe, and Lake Baikal/East Asia, and the positive anomalous centers appear in the central-eastern Atlantic and central Europe between $40^{\circ}$ and $60^{\circ} \mathrm{N}$. These anomalous centers are generally consistent with the observation (shown in Figs. 7a and 8b), which thus demonstrates the impact of the northwestern Atlantic SST anomalies on the anomalous wave train in extratropical Eurasia and the anomalous circulation in Lake Baikal.

Many studies have pointed out that North Atlantic SST can influence Asian climate through teleconnection wave trains (Barnston and Livezey 1987; Watanabe 2004; Wu et al. 2009; Wang et al. 2011; Wu et al. 2011; Liu et al. 2012; Zhou and Wu 2015; Li et al. 2018; Han et al. 2018). For example, Barnston and Livezey (1987) suggested that the east Atlantic/west Russia (EA/WR) pattern was an important planetary-scale circulation pattern from the eastern Atlantic, which can influence the Asian winter monsoon (Wang et al. 2011). In this study, we further exhibit an interdecadal link between the TP water vapor and the North Atlantic SST during summer.

\section{Summary and discussion}

In this study, we investigate the change of summer water vapor over the entire TP using the ERA-Interim monthly mean reanalysis. On the climate mean state, the TP water vapor change is closely associated with the water vapor budgets on the western, southern, and northern boundaries. During 1979-2014, the TP water vapor exhibits remarkable interdecadal and interannual variations. On the interdecadal scale, the TP is getting wet, with a dry phase during 1979-94 and a wet phase during 1995-2014, which is mainly due to a strong reduction of the water vapor export on the eastern boundary. The increased water vapor imports from the southern and western boundaries also contribute to this wetting. Associated with the increase in water vapor in the TP are the increases of the local rainfall and surface runoff.

Composite analyses show that the TP water vapor change is closely associated with an atmospheric 
(a)

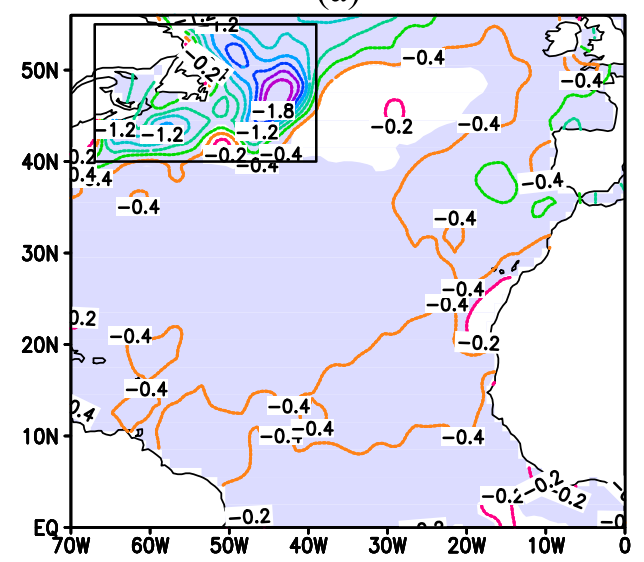

(b)

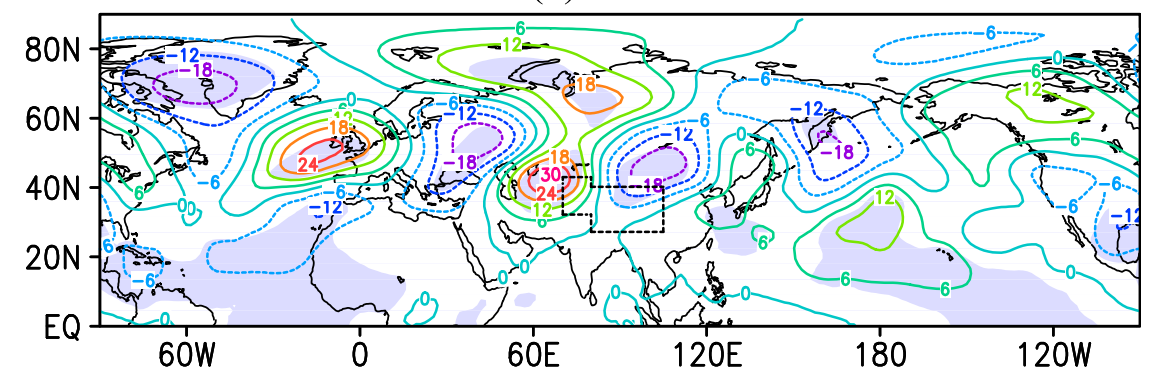

(c)

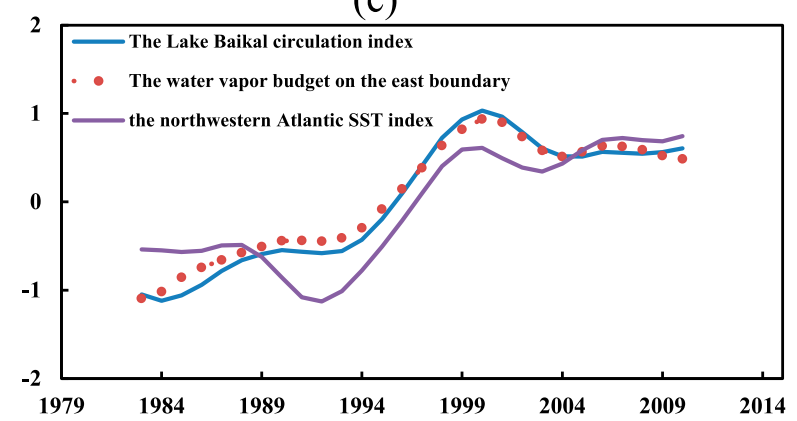

FIG. 8. (a) As in Fig. 5a, but for summer SST $\left({ }^{\circ} \mathrm{C}\right)$, in which the box $\left(40^{\circ}-55^{\circ} \mathrm{N}, 67^{\circ}-39^{\circ} \mathrm{W}\right)$ is for the key region of the northwestern Atlantic SST; (b) the regressed summer 200-hPa eddy geopotential height (gpm) against the Atlantic SST index (with an opposite sign) on the interdecadal scale, in which the shaded regions are significant at the $90 \%$ confidence level; and (c) the time series of $B_{E}$, the Lake Baikal circulation index, and the northwestern Atlantic SST index during summer on the interdecadal time scale.

circulation anomaly near Lake Baikal on the interdecadal scale. The TP climate is drier when a deep cyclonic anomaly appears near Lake Baikal during summer, and vice versa. The cyclonic (anticyclonic) circulation anomaly near Lake Baikal is related to a large-scale extratropical anomalous wave train from the northwestern Atlantic to East Asia, with negative (positive) anomalous centers in Baffin Bay, central Europe, and Lake Baikal and positive (negative) anomalous centers in the central-eastern Atlantic and western Asia. The anomalous wave energy propagates from the extratropical North Atlantic toward East Asia. Meanwhile, significant negative anomalies of SST appear in the northwestern Atlantic during summer. These results imply that the anomalous wave train is related to the variation of SST in the northwestern Atlantic. The model sensitivity experiments demonstrate an impact of the Atlantic SST anomalies. Corresponding to a 


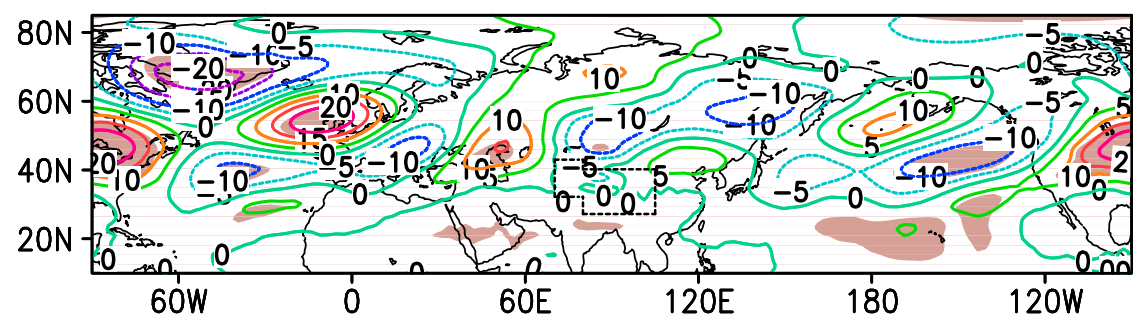

FIG. 9. The composite difference of summer 200-hPa eddy geopotential height between the experiments CAM3_N and CAM3_Control, in which the shaded regions are significant at the $90 \%$ confidence level.

decrease of the summer northwestern Atlantic SST in the model, an anomalous wave train similar to the observation appears in the extratropics from the northwestern Atlantic to East Asia, with an anomalous low near Lake Baikal.

Meanwhile, it is noted that the interdecadal changing point of $B_{E}$ (important to the interdecadal change of $B_{T}$ ) occurs around 1996 (not in 1994). To examine a possible effect of the difference in changing points on our conclusion, the above composite analyses between 1979-96 and 1997-2014 are repeated (shown in Figs. 10 and 11). Comparing Figs. 10 and 11 with the composite figures between 1979-94 and 1995-2014, we see similar anomalies in PW, rainfall, atmospheric circulation, and SST, which shows that this small difference in changing points does not change our conclusion.

The Atlantic SST changes have a close relationship with the Atlantic multidecadal oscillation (AMO) variations in recent decades (e.g., Ting et al. 2009; Msadek et al. 2011; Sutton and Dong 2012). The (a)

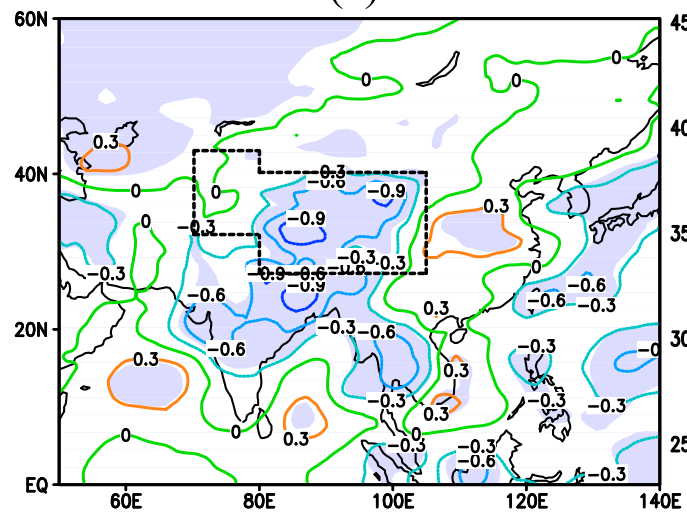

(b)

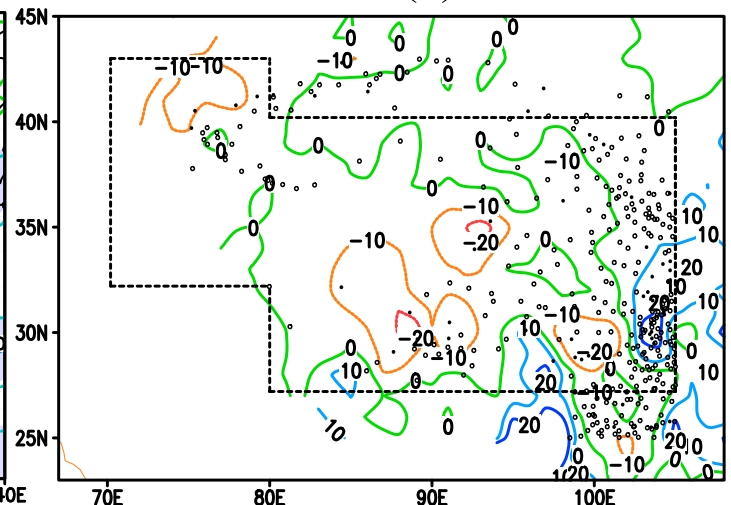

(c)

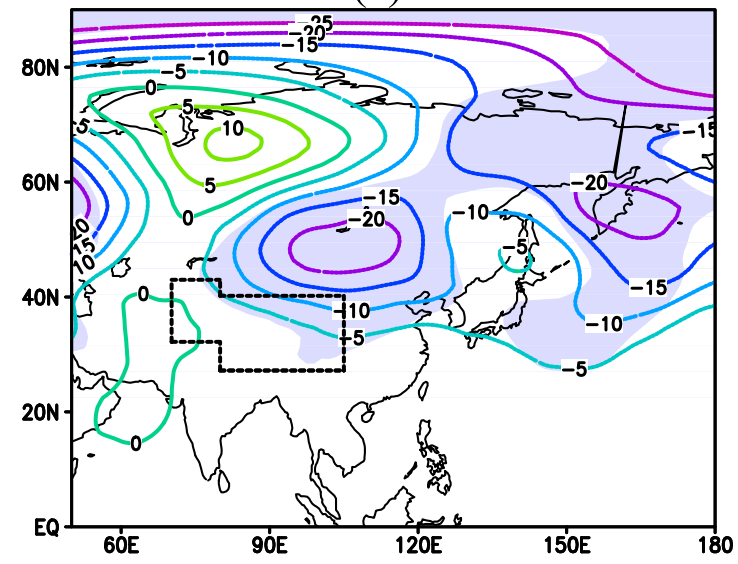

FIG. 10. (a) As in Fig. 3c, but between 1979-96 and 1997-2014. (b) As in Fig. 4b, but between 1979-96 and 19972014. (c) As in Fig. 5a, but between 1979-96 and 1997-2014. 
(a)

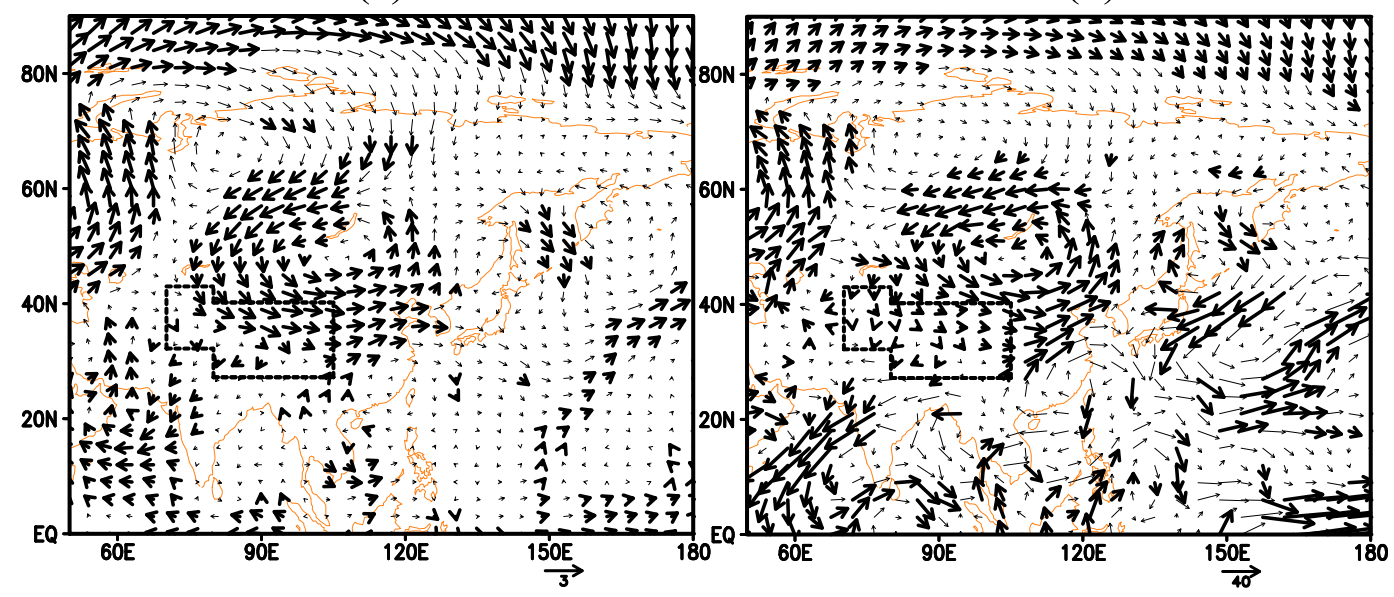

(c)

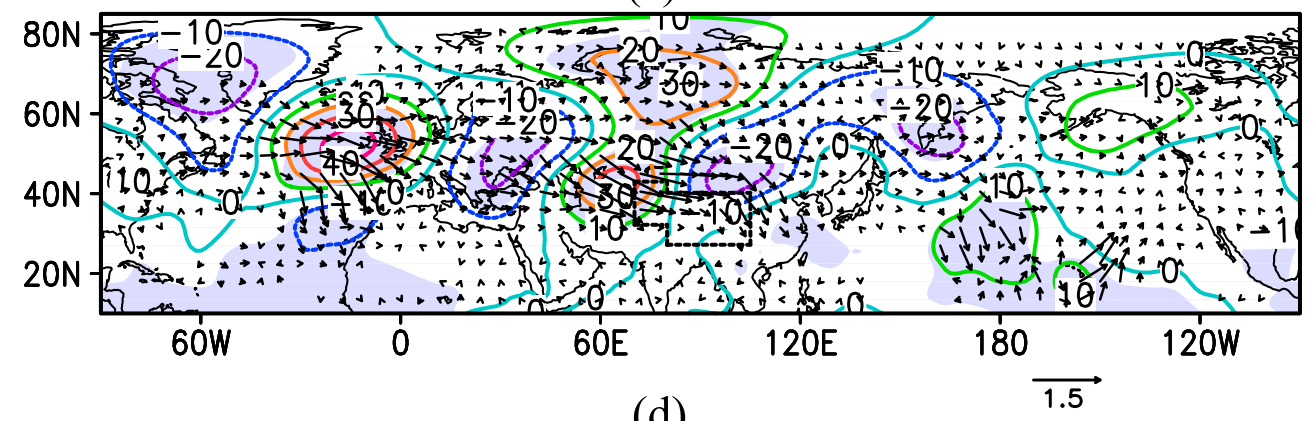

(d)

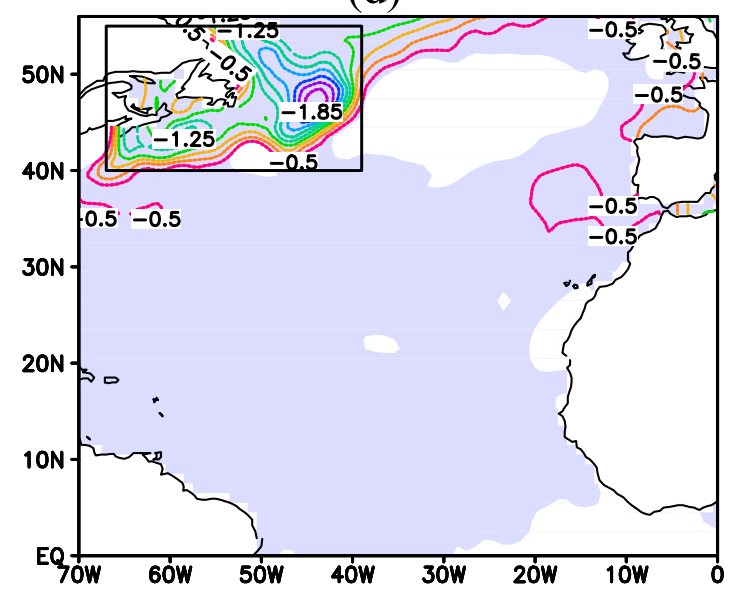

FIG. 11. (a), (b) As in Figs. 6a and 6b, but between 1979-96 and 1997-2014, respectively. (c) As in Fig. 7a, but between 1979-96 and 1997-2014. (d) As in Fig. 8a, but between 1979-96 and 1997-2014.

correlation coefficient is 0.71 between the AMO index [following Trenberth and Shea (2006)] and the northwestern Atlantic SST index during 1979-2014, significant at the $99 \%$ confidence level. It shows that the SST index actually reflects the variation of the AMO. Studies have shown the AMO variations are closely related to the Atlantic meridional overturning circulation
(AMOC) (Delworth and Mann 2000; Knight et al. 2006). However, we also note that the northwestern Atlantic SST is just one of the influence factors to the interdecadal change of the water vapor budget in the TP. Based on recent studies (e.g., Coumou et al. 2014; Tang et al. 2014; Cohen et al. 2014; Horton et al. 2015), the Arctic amplification may affect the interdecadal change 
of the TP water vapor. A collaborative influence of these factors on the TP water vapor shall be investigated in the future.

Acknowledgments. The authors wish to thank three referees for their constructive comments. This work is jointly sponsored by the National Science Foundation of China (91637312, 41305082, 41775084, 91437218, and 41772173), the Strategic Priority Research Program of Chinese Academy of Sciences (XDA20100300), the Third Tibetan Plateau Atmospheric Scientific Experiment (GYHY201406001), and the co-sponsored project by Sichuan Meteorological Bureau and Nanjing University of Information Science \& Technology (SCJXHZ04).

\section{REFERENCES}

Bao, X., and F. Zhang, 2013: Evaluation of NCEP-CFSR, NCEPNCAR, ERA-Interim, and ERA-40 reanalysis datasets against independent sounding observations over the Tibetan Plateau. J. Climate, 26, 206-214, https://doi.org/10.1175/JCLID-12-00056.1.

Barnston, A., and R. Livezey, 1987: Classification, seasonality and persistence of low-frequency atmospheric circulation patterns. Mon. Wea. Rev., 115, 1083-1126, https://doi.org/10.1175/15200493(1987)115<1083:CSAPOL > 2.0.CO;2.

Bothe, O., K. Fraedrich, and X. Zhu, 2010: The large-scale circulations and summer drought and wetness on the Tibetan Plateau. Int. J. Climatol., 30, 844-855, https://doi.org/10.1002/ joc.1946.

,$- \ldots$, and -2011 : Large-scale circulations and Tibetan Plateau summer drought and wetness in a high-resolution climate model. Int. J. Climatol., 31, 832-846, https://doi.org/ $10.1002 /$ joc. 2124.

Chen, B., X. Xu, S. Yang, and W. Zhang, 2012: On the origin and destination of atmospheric moisture and air mass over the Tibetan Plateau. Theor. Appl. Climatol., 110, 423-435, https:// doi.org/10.1007/s00704-012-0641-y.

Chen, D., and Coauthors, 2015: Assessment of past, present and future environmental changes on the Tibetan Plateau (in Chinese). Chin. Sci. Bull., 60, 3025-3035, https://doi.org/ 10.1360/N972014-01370.

Cohen, J., and Coauthors, 2014: Recent Arctic amplification and extreme mid-latitude weather. Nat. Geosci., 7, 627-637, https://doi.org/10.1038/ngeo2234.

Collins, W. D., and Coauthors, 2004: Description of the NCAR Community Atmosphere Model (CAM 3.0). NCAR Tech. Note NCAR/TN-464+STR, 214 pp., https://doi.org/10.5065/ D63N21CH.

Coumou, D., V. Petoukhov, S. Rahmstorf, S. Petria, and H. Schellnhuber, 2014: Quasi-resonant circulation regimes and hemispheric synchronization of extreme weather in boreal summer. Proc. Natl. Acad. Sci. USA, 111, 12331-12336, https://doi.org/10.1073/pnas.1412797111.

Curio, J., F. Maussion, and D. Scherer, 2015: A 12-year highresolution climatology of atmospheric water transport over the Tibetan Plateau. Earth Syst. Dyn., 6, 109-124, https:// doi.org/10.5194/esd-6-109-2015.

Dee, D. P., and Coauthors, 2011: The ERA-Interim reanalysis: Configuration and performance of the data assimilation sys- tem. Quart. J. Roy. Meteor. Soc., 137, 553-597, https://doi.org/ 10.1002/qj.828.

Delworth, T. L., and M. E. Mann, 2000: Observed and simulated multidecadal variability in the Northern Hemisphere. Climate Dyn. 16, 661-676, https://doi.org/10.1007/s003820000075.

Deser, C., and A. S. Phillips, 2009: Atmospheric circulation trends, 1950-2000: The relative roles of sea surface temperature forcing and direct atmospheric radiative forcing. J. Climate, 22, 396-413, https://doi.org/10.1175/2008JCLI2453.1.

Ding, Q., and B. Wang, 2005: Circumglobal teleconnection in the Northern Hemisphere summer. J. Climate, 18, 3483-3505, https://doi.org/10.1175/JCLI3473.1.

Ding, Y., and G. Hu, 2003: A study on water vapor budget over China during the 1998 severe flood periods (in Chinese). Acta Meteor. Sin., 61, 129-145.

Enomoto, T., B. Hoskins, and Y. Matsuda, 2003: The formation mechanism of the Bonin high in August. Quart. J. Roy. Meteor. Soc., 129, 157-178, https://doi.org/10.1256/qj.01.211.

Feng, L., and T. Zhou, 2012: Water vapor transport for summer precipitation over the Tibetan Plateau: Multi-dataset analysis. J. Geophys. Res., 117, D20114, https://doi.org/10.1029/2011JD017012.

Fu, R., and Coauthors, 2006: Short circuit of water vapor and polluted air to the global stratosphere by convective transport over the Tibetan Plateau. Proc. Natl. Acad. Sci. USA, 103, 5664-5669, https://doi.org/10.1073/pnas.0601584103.

Gao, Y., C. Lan, and Y. Zhang, 2014: Changes in moisture flux over the Tibetan Plateau during 1979-2011 and possible mechanisms. J. Climate, 27, 1876-1893, https://doi.org/10.1175/JCLID-13-00321.1.

Gettelman, A., D. E. Kinnison, T. J. Dunkerton, and G. P. Brasseur, 2004: Impact of monsoon circulations on the upper troposphere and lower stratosphere. J. Geophys. Res., 109, D22101, https://doi.org/10.1029/2004JD004878.

Hack, J. J., J. M. Caron, S. G. Yeager, K. W. Oleson, M. M. Holland, J. E. Truesdale, and P. J. Rasch, 2006: Simulation of the global hydrological cycle in the CCSM Community Atmosphere Model version 3 (CAM3): Mean features. J. Climate, 19, 2199-2221, https://doi.org/10.1175/JCLI3755.1.

Han, T., S. He, X. Hao, and H. Wang, 2018: Recent interdecadal shift in the relationship between Northeast China's winter precipitation and the North Atlantic and Indian Oceans. Climate. Dyn., 50, 1413-1424, https://doi.org/10.1007/s00382-0173694-x.

Held, M. I., and B. J. Soden, 2006: Robust responses of the hydrological cycle to global warming. J. Climate, 19, 5686-5699, https://doi.org/10.1175/JCLI3990.1.

Horton, D. E., N. C. Johnson, D. Singh, D. L. Swain, B. Rajaratnam, and N. S. Diffenbaugh, 2015: Contribution of changes in atmospheric circulation patterns to extreme temperature trends. Nature, 522, 465-469, https://doi.org/10.1038/ nature 14550.

Immerzeel, W. W., L. P. van Beek, and M. F. Bierkens, 2010: Climate change will affect the Asian water towers, Science, 328, 1382-1385, https://doi.org/10.1126/science.1183188.

Jin, S., Y. Zhang, and H. Wu, 2013: Study on glacial advancement and retreatment in Geladandong region of Changjiangyuan in recent 40 years (in Chinese). J. Nat. Resour., 28, 2095-2104.

Kang, S., Y. Xu, Q. You, W.-A. Flügel, N. Pepin, and T. Yao, 2010: Review of climate and cryospheric change in the Tibetan Plateau. Environ. Res. Lett., 5, 015101, https://doi.org/10.1088/ 1748-9326/5/1/015101.

Kim, Y., and G. Wang, 2007: Impact of initial soil moisture anomalies on subsequent precipitation over North America in the Coupled 
Land-Atmosphere Model CAM3-CLM3. J. Hydrometeor., 8 , 513-533, https://doi.org/10.1175/JHM611.1.

Knight, J. R., C. K. Folland, and A. A. Scaife, 2006: Climate impacts of the Atlantic multidecadal oscillation. Geophys. Res. Lett., 33, L17706, https://doi.org/10.1029/2006GL026242.

Lau, W. K.-M., K. Kim, and J. Lee, 2004: Interannual variability, global teleconnection and potential predictability associated with the Asian summer monsoon. East Asian Monsoon, C. P Chang, Ed., World Scientific, 153-176.

Li, G., J. Chen, X. Wang, X. Luo, D. Yang, W. Zhou, Y. Tan, and H. Yan, 2018: Remote impact of North Atlantic sea surface temperature on rainfall in southwestern China during boreal spring. Climate Dyn., 50, 541-553, https://doi.org/10.1007/ s00382-017-3625-x.

Li, M., X. Zhang, and C. Xie, 2014: Cause analysis on typical abnormal year of water vapor in the upper troposphere over Qinghai-Xizang Plateau (in Chinese). Plateau Meteor., 33, 1197-1203.

Li, S., D. Li, and P. Zhao, 2009: The climatic characteristics of vapor transportation in rainy season of the origin area of three rivers in Qinghai-Xizang Plateau (in Chinese). Acta Meteor. Sin., 67, 591-598.

Liang, H., J. Liu, and S. Li, 2006: Analysis of precipitable water vapor source distribution and its seasonal variation characteristics over Tibetan Plateau and its surroundings (in Chinese). J. Nat. Resour., 24, 526-534, https://doi.org/ 10.3321/j.issn:1000-3037.2006.04.004.

Liu, G., L. Ji, and R. Wu, 2012: An east-west SST anomaly pattern in the midlatitude North Atlantic Ocean associated with winter precipitation variability over eastern China. J. Geophys. Res., 117, D15104, https://doi.org/10.1029/2012JD017960.

Liu, X., and B. Chen, 2000: Climatic warming in the Tibetan Plateau during recent decades. Int. J. Climatol. 20, 1729-1742, https://doi.org/10.1002/1097-0088(20001130)20:14<1729:: AID-JOC556>3.0.CO;2-Y.

_- and Z. Yin, 2001: Spatial and temporal variation of summer precipitation over the eastern Tibetan plateau and the North Atlantic Oscillation. J. Climate, 14, 2896-2909, https:// doi.org/10.1175/1520-0442(2001)014<2896:SATVOS >2.0. $\mathrm{CO} ; 2$.

Liu, X. M., H. Zheng, M. Zhang, and C. Liu, 2011: Identification of dominant climate factor for pan evaporation trend in the Tibetan Plateau. J. Geogr. Sci., 21, 594-608, https://doi.org/ 10.1007/s11442-011-0866-1.

Lorenz, D. J., and E. T. DeWeaver, 2007: The response of the extratropical hydrological cycle to global warming. J. Climate, 20, 3470-3484, https://doi.org/10.1175/JCLI4192.1.

Luo, H., and M. Yanai, 1984: The large-scale circulation and heat sources over the Tibetan Plateau and surrounding areas during the early summer of 1979: Part II: Heat and moisture budgets. Mon. Wea. Rev., 112, 966-989, https://doi.org/ 10.1175/1520-0493(1984)112<0966:TLSCAH > 2.0.CO;2.

Moore, G. W. K., 2012: Surface pressure record of Tibetan Plateau warming since the 1870s. Quart. J. Roy. Meteor. Soc., 138, 1999-2008, https://doi.org/10.1002/qj.1948.

Msadek, R., C. Frankignou, and L. Z. X. Li, 2011: Mechanisms of the atmospheric response to North Atlantic multidecadal variability: A model study. Climate Dyn., 36, 1255-1276, https://doi.org/10.1007/s00382-010-0958-0.

Qian, K., X. Wang, J. Lv, and L. Wan, 2014: The wavelet correlative analysis of climatic impacts on runoff in the source region of Yangtze River, in China. Int. J. Climatol., 34, 2019-2032, https://doi.org/10.1002/joc.3818.
Rayner, N. A., D. E. Parker, E. B. Horton, C. K. Folland, L. V. Alexander, D. P. Rowell, E. C. Kent, and A. Kaplan, 2003: Global analyses of sea surface temperature, sea ice, and night marine air temperature since the late nineteenth century. J. Geophys. Res., 108, 4407, https://doi.org/10.1029/ 2002JD002670.

Ren, Q., C. Zhou, J. He, S. Cen, and M. Deng, 2017: Impact of preceding Indian Ocean sea surface temperature anomaly on water vapor content over the Tibetan Plateau moist pool in summer and its possible reason (in Chinese). Chin. J. Atmos. Sci., 41, 648-658.

Schiemann, R., D. Lüthi, and C. Schär, 2009: Seasonality and interannual variability of the westerly jet in the Tibetan Plateau region. J. Climate, 22, 2940-2957, https://doi.org/10.1175/ 2008JCLI2625.1.

Seager, R., N. Naik, and G. A. Vecchi, 2010: Thermodynamic and dynamic mechanisms for large-scale changes in the hydrological cycle in response to global warming. J. Climate, 23, 4651-4668, https://doi.org/10.1175/2010JCLI3655.1.

Shi, X., and X. Shi, 2008: Climatological characteristics of summertime moisture budget over the southeast part of Tibetan Plateau with their impacts (in Chinese). J. Appl. Meteor. Sci., 19, 41-46.

Shi, X. H., X. Xu, and X. Cheng, 2009: Premonitory of water vapor transport in the upstream key region over the Tibetan Plateau during the 2008 snowstorm disaster in South China (in Chinese). Acta Meteor. Sin., 67, 478-487, https://doi.org/10.3321/ j.issn:0577-6619.2009.03.015.

Simmonds, I., D. Bi, and P. Hope, 1999: Atmospheric water vapor flux and its association with rainfall over China in summer. J. Climate, 12, 1353-1367, https://doi.org/10.1175/1520-0442(1999)012<1353: AWVFAI $>2.0 . \mathrm{CO} ; 2$

Sohn, B. J., and S. C. Park, 2010: Strengthened tropical circulations in past three decades inferred from water vapor transport. J. Geophys. Res., 115, D15112, https://doi.org/10.1029/ 2009JD013713.

Sugimoto, S., K. Ueno, and W. Sha, 2008: Transportation of water vapor into the Tibetan Plateau in the case of a passing synoptic-scale trough. J. Meteor. Soc. Japan, 86, 935-949, https://doi.org/10.2151/jmsj.86.935.

Sun, B., and H. Wang, 2014: Moisture sources of semiarid grassland in China using the Lagrangian particle model FLEXPART. J. Climate, 27, 2457-2474, https://doi.org/10.1175/JCLI-D-13-00517.1.

Sutton, R. T., and B. Dong, 2012: Atlantic Ocean influence on a shift in European climate in the 1990s. Nat. Geosci., 5, 788792, https://doi.org/10.1038/ngeo1595.

Takaya, K., and H. Nakamura, 1997: A formulation of a waveactivity flux for stationary Rossby waves on a zonally varying basic flow. Geophys. Res. Lett., 24, 2985-2988, https://doi.org/ 10.1029/97GL03094.

, and - 2001: A formulation of a phase-independent waveactivity flux for stationary and migratory quasigeostrophic eddies on a zonally varying basic flow. J. Atmos. Sci., 58, 608-627, https:// doi.org/10.1175/1520-0469(2001)058<0608:AFOAPI >2.0.CO;2.

Tang, J., H. Cao, and J. Chen, 2018: Changes of hydrometeorological factors and the relationships with large-scale circulation factors in the source region of the Yangtze River (in Chinese). J. Nat. Resour., 33, 840-852, https://doi.org/ 10.11849/zrzyxb.20170413.

Tang, Q., X. Zhang, and J. A. Francis, 2014: Extreme summer weather in northern mid-latitudes linked to a vanishing cryosphere. Nat. Climate Change, 4, 45-50, https://doi.org/10.1038/ nclimate2065. 
Tao, S., and L. Yi, 1999: The role of Tibetan Plateau on water cycle in the Asian monsoon region. The Theory Advances in the Second Tibetan Plateau Experiment of Atmospheric Sciences (in Chinese). S. Tao et al., Eds., China Meteorological Press, 204-214.

Ting, M., Y. Kushnir, R. Seager, and C. Li, 2009: Forced and internal twentieth-century SST trends in the North Atlantic. J. Climate, 22, 1469-1481, https://doi.org/10.1175/ 2008JCLI2561.1.

Trenberth, K. E., and D. J. Shea, 2006: Atlantic hurricanes and natural variability in 2005. Geophys. Res. Lett., 33, L12704, https://doi.org/10.1029/2006GL026894.

Ueda, H., H. Kamahori, and N. Yamasaki, 2003: Seasonal contrasting features of heat and moisture budgets between the eastern and western Tibetan Plateau during the GAME IOP. J. Climate., 16, 2309-2324, https://doi.org/10.1175/2757.1.

Wan, W., P. Xiao, X. Feng, H. Li, R. Ma, H. Duan, and L. Zhao, 2014: Monitoring lake changes of Qinghai-Tibetan Plateau over the past 30 years using satellite remote sensing data. Chin. Sci. Bull., 59, 1021-1035, https://doi.org/10.1007/s11434014-0128-6.

Wang, B., R. Wu, and K. M. Lau, 2001: Interannual variability of the Asian summer monsoon: Contrasts between the Indian and the western North Pacific-East Asian monsoons. J. Climate, 14, 4073-4090, https://doi.org/10.1175/1520-0442(2001)014<4073: IVOTAS $>2.0 . \mathrm{CO} ; 2$.

Wang, Xiao, Y. Gong, and S. Cen, 2009: Characteristics of the moist pool and its moisture transports over Qinghai-Xizang Plateau in summer half year (in Chinese). Acta Geogr. Sin., 64, 601-608, https://doi.org/10.3321/j.issn:0375-5444.2009.05.009.

Wang, Xin, C. Wang, W. Zhou, D. Wang, and J. Song, 2011: Teleconnected influence of North Atlantic sea surface temperature on the El Niño onset. Climate Dyn., 37, 663-676, https:// doi.org/10.1007/s00382-010-0833-z.

Wang, Y., L. Wu, J. Xu, and S. Liu, 2013: Variation and uncertainty analysis of the glaciers in the past 50 years in Geladandong of Tibetan Plateau (in Chinese). J. Glaciol. Geocryology, 35, 255-262.

Wang, Z., A. Duan, S. Yang, and K. Ullah, 2017: Atmospheric moisture budget and its regulation on the variability of summer precipitation over the Tibetan Plateau. J. Geophys. Res. Atmos., 122, 614-630, https://doi.org/10.1002/2016JD025515.

Watanabe, M., 2004: Asian jet waveguide and a downstream extension of the North Atlantic Oscillation. J. Climate, 17, 46744691, https://doi.org/10.1175/JCLI-3228.1.

Webster, P., V. O. Magaña, T. N. Palmer, J. Shukla, R. A. Tomas, M. Yanai, and T. Yasunari, 1998: Monsoons: Processes, predictability, and the prospects for prediction. J. Geophys. Res., 103, 14 451-14 510, https://doi.org/10.1029/97JC02719.

Wu, R., S. Yang, S. Liu, L. Sun, Y. Lian, and Z. Gao, 2011: Northeast China summer temperature and North Atlantic SST. J. Geophys. Res., 116, D16116, https://doi.org/10.1029/2011JD015779.

Wu, S., Y. Yin, D. Zheng, and Q. Yang, 2007: Climatic trends over the Tibetan Plateau during 1971-2000. J. Geogr. Sci., 17, 141151, https://doi.org/10.1007/s11442-007-0141-7.

Wu, Z., B. Wang, J. Li, and F. Jin, 2009: An empirical seasonal prediction model of the East Asian summer monsoon using ENSO and NAO. J. Geophys. Res., 114, D18120, https:// doi.org/10.1029/2009JD011733.

Xie, C., M. Li, and X. Zhang, 2014: Characteristics of summer atmospheric water resources and its causes over the Tibetan Plateau in recent 30 years (in Chinese). J. Nat. Resour., 29, 979-989.
Xie, P., and P. A. Arkin, 1997: Global precipitation: A 17-year monthly analysis based on gauge observations, satellite estimates and numerical model outputs. Bull. Amer. Meteor. Soc., 78, 2539-2558, https://doi.org/10.1175/1520-0477(1997) $078<2539$ :GPAYMA $>2.0$. CO;2.

$\mathrm{Xu}, \mathrm{X} ., 2009$ : The effects of sensitive region over Tibetan Plateau on disastrous weather and climate and its monitoring (in Chinese). Eng. Sci., 11, 96-107.

— S. Tao, J. Wang, L. Chen, L. Zhou, and X. Wang, 2002: The relationship between water vapor transport features of Tibetan Plateau-Monsoon "large triangle" affecting region and drought-flood abnormality of China (in Chinese). Acta Meteor. Sin., 60, 257-267.

— C. Lu, X. Shi, and S. Gao, 2008: World water tower: An atmospheric perspective. Geophys. Res. Lett., 35, L20815, https://doi.org/10.1029/2008GL035867.

— T. Zhao, C. Lu, and X. Shi, 2014: Characteristics of the water cycle in the atmosphere over the Tibetan Plateau (in Chinese) Acta Meteor. Sin., 72, 1079-1095.

Yang, J., Y. Ding, S. Liu, A. Lu, and R. Chen, 2003: Glacier change and its effect on surface runoff in the source regions of the Yangtze and Yellow Rivers (in Chinese). J. Nat. Resour., 18, 595-602.

Yang, K., B. Ye, D. Zhou, B. Wu, T. Foken, J. Qin, and Z. Zhou, 2011: Response of hydrological cycle to recent climate changes in the Tibetan Plateau. Climatic Change, 109, 517-534, https:// doi.org/10.1007/s10584-011-0099-4.

- , H. Wu, J. Qin, C. Lin, W. Tang, and Y. Chen, 2014: Recent climate changes over the Tibetan Plateau and their impacts on energy and water cycle: A review. Global Planet. Change, 112, 79-91, https://doi.org/10.1016/j.gloplacha.2013.12.001.

Yao, T., and Coauthors, 2012: Different glacier status with atmospheric circulations in Tibetan Plateau and surroundings. Nat. Climate Change, 2, 663-667, https://doi.org/10.1038/nclimate1580.

Ye, D., and G. Wu, 1998: The role of the heat source of the Tibetan Plateau in the general circulation. Meteor. Atmos. Phys., 67, 181-198, https://doi.org/10.1007/BF01277509.

You, Q., J. Min, W. Zhang, N. Pepin, and S. Kang, 2015: Comparison of multiple datasets with gridded precipitation observations over the Tibetan Plateau. Climate Dyn., 45, 791-806, https:// doi.org/10.1007/s00382-014-2310-6.

Zhang, C., Q. Tang, and D. Chen, 2017: Recent changes in the moisture source of precipitation over the Tibetan Plateau. J. Climate, 30, 1807-1819, https://doi.org/10.1175/JCLI-D-150842.1.

Zhang, L., Y. Tang, and X. Yang, 2014: Overall and local changing patterns of main glaciers and their responses to climate change in Geladandong area of Yangtze headwater region during 1969-2012 (in Chinese). Arid Land Geogr., 37, 212-221, https://doi.org/10.13826/j.cnki.cn65-1103/x.2014.02.011.

Zhang, X., Y. Ren, Z. Yin, Z. Lin, and D. Zheng, 2009: Spatial and temporal variation patterns of reference evapotranspiration across the Qinghai-Tibetan Plateau during 1971-2004. J. Geophys. Res., 114, D15105, https://doi.org/10.1029/2009JD011753.

Zhang, Y., C. Liu, Y. Tang, and Y. Yang, 2007: Trends in pan evaporation and reference and actual evapotranspiration across the Tibetan Plateau. J. Geophys. Res., 112, D12110, https://doi.org/10.1029/2006JD008161.

Zhang, Y. W., D. Wang, P. Zhai, G. Gu, and J. He, 2013: Spatial distributions and seasonal variations of tropospheric water vapor content over the Tibetan Plateau. J. Climate, 26, 56375654, https://doi.org/10.1175/JCLI-D-12-00574.1.

Zhao, P., and L. X. Chen, 2001a: Climatic features of atmospheric heat source/sink over the Qinghai-Xizang Plateau in 35 years 
and its relation to rainfall in China. Sci. China, 44D, 858-864, https://doi.org/10.1007/BF02907098.

, and _ , 2001b: Interannual variability of atmospheric heat source/sink over the Qinghai-Xizang (Tibetan) Plateau and its relation to circulation. Adv. Atmos. Sci., 18, 106-116, https:// doi.org/10.1007/s00376-001-0007-3.

_- S. Yang, M. Jian, and J. Chen, 2011: Relative controls of Asian-Pacific summer climate by Asian land and tropicalNorth Pacific sea surface temperature. J. Climate, 24, 41654188, https://doi.org/10.1175/2011JCLI3915.1.

, R. Wu, Z. Wen, J. Chen, and H. Wang, 2012: Asian origin of interannual variations of summer climate over the extratropical North Atlantic Ocean. J. Climate, 25, 6594-6609, https://doi.org/10.1175/JCLI-D-11-00617.1.

_ , and Coauthors, 2018: The third atmospheric scientific experiment for understanding the Earth-atmosphere coupled system over the Tibetan Plateau and its effects. Bull. Amer. Meteor. Soc., 99, 757-776, https://doi.org/10.1175/BAMS-D-16-0050.1.

Zhou, C., X. Jiang, and Y. Li, 2009: Features of climate change of water vapor resource over eastern region of the Tibetan
Plateau and its surroundings (in Chinese). Plateau Meteor., 28, 55-63.

-, D. Qi, Y. Li, and D. Chen, 2015: Long-distance-relayed water vapor transport east of Tibetan plateau and its impacts. J. Trop. Meteor., 21, 43-54.

- M. Deng, and D. Qi, 2017: Characteristics of the moist pool over the Qinghai-Tibetan Plateau and its variation (in Chinese). Plateau Meteor., 36, 294-306.

Zhou, L., and R. Wu, 2015: Interdecadal variability of winter precipitation in Northwest China and its association with the North Atlantic SST change. Int. J. Climatol., 35, 1172-1179, https://doi.org/10.1002/joc.4047.

Zhou, S., P. Wu, C. Wang, and J. Han, 2012: Spatial distribution of atmospheric water vapor and its relationship with precipitation in summer over the Tibetan Plateau (in Chinese). J. Geogr. Sci., 22, 795-809, https://doi.org/10.1007/S11442-0120964-8.

Zhuo, G., B. Luo, and C. Zhou, 2012: Climate characteristics of water vapor transport over Tibet region in 1980-2009 (in Chinese). J. Glaciol. Geocryol., 34, 783-794. 